\section{SUMMARY REPORT OF}

NIST'S

INDUSTRY-GOVERNMENT CONSORTIUM

RESEARCH PROGRAM

ON FLOWMETER

INSTALLATION EFFECTS

WITH EMPHASIS ON

THE RESEARCH PERIOD

NOVEMBER 1988 -

MAY 1989
G. E. Mattingly

T. T. Yeh

U.S. DEPARTMENT OF COMMERCE National Institute of standards and Tochnology Natlonal Moasuroment Laboratory Centor for Chemical Technolosy Fluld flow croup Chemleal Process Motrology Divislon Galthorsburs, MD 20899
U.S. DEPARTMENT OF COMMERCE Robert A. Mosbacher, Secretary NATIONAL INSTIUUTE OF STANDARDS AND TECHNOLOQY

Dr. John W. Lyons, Director 

SUMMARY REPORT OF NIST'S

INDUSTRY-GOVERNMENT CONSORTIUM

RESEARCH PROGRAM

ON FLOWMETER

INSTALLATION EFFECTS

WITH EMPHASIS ON

THE RESEARCH PERIOD

NOVEMBER 1988 -

MAY 1989
G. E. Mattingly

T. T. Yeh

U.S. DEPARTMENT OF COMMERCE Natlonal Institute of standards and Tochnology

Natlonal Measurement Laboratory Center for Chemlcal Technology

Fuld Flow Group

Chemlcal Process Metrology Division

Calthersburs, MD 20899

Aprll 1990

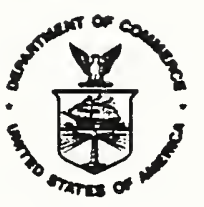

U.S. DEPARTMENT OF COMMERCE Robert A. Mosbacher, secretary MATIONAL INSTTUTE OF STANDARDS AND TECHNOLOQY

Dr. John W. Lyons, Director 

The research results reported in this document were produced with the support of a National Institute of Standards and Technology (NIST) initiated industrygovernment consortium. In this mode of operation, there is a high degree of interaction between the representatives of the consortium member companies and the NIST researchers. These interactions include: (1) the planning of the specific focus of the NIST research efforts, (2) the analyses of the results obtained, and (3) the conclusions drawn for the particular phase of the work. For this reason, it is pertinent to acknowledge both the support given to this phase of the research program and the technical contributions made by the representatives of the consortium members.

The current consortium as of May 1989 is, alphabetically:

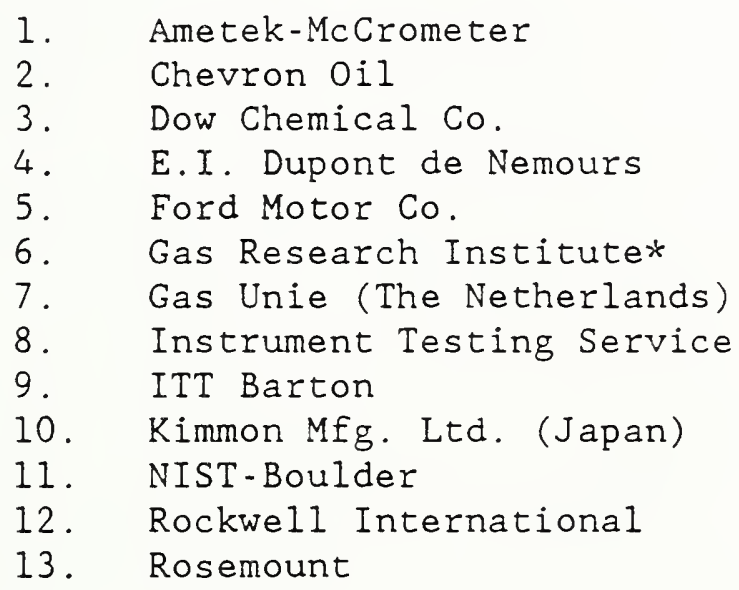

*Specific acknowledgment is due to Dr. Kiran M. Kothari of the Gas Research Institute (GRI). Both his support of this program and his technical inputs in the analyses of results and in the conclusions drawn are gratefully acknowledged. 



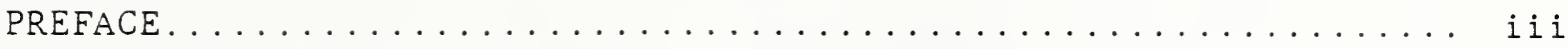

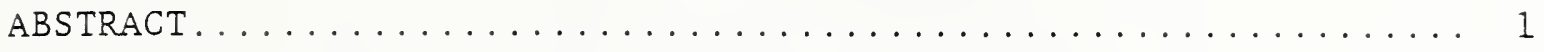

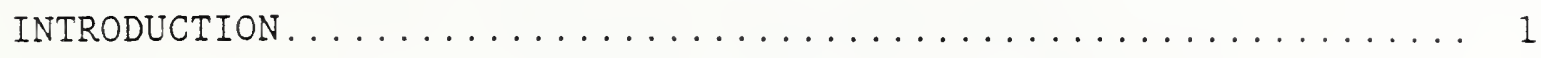

EXPERIMENTAL RESULTS ..................... 3

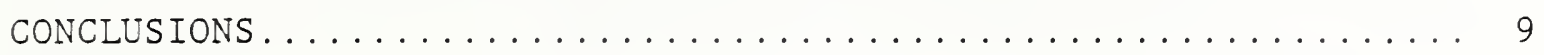

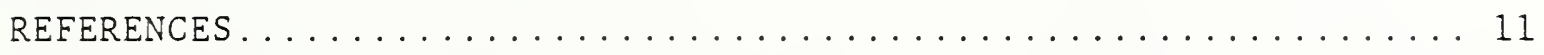

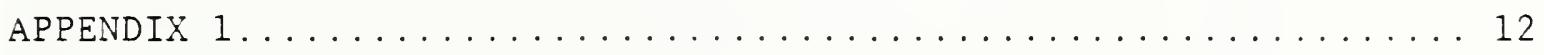

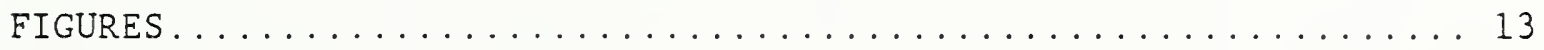





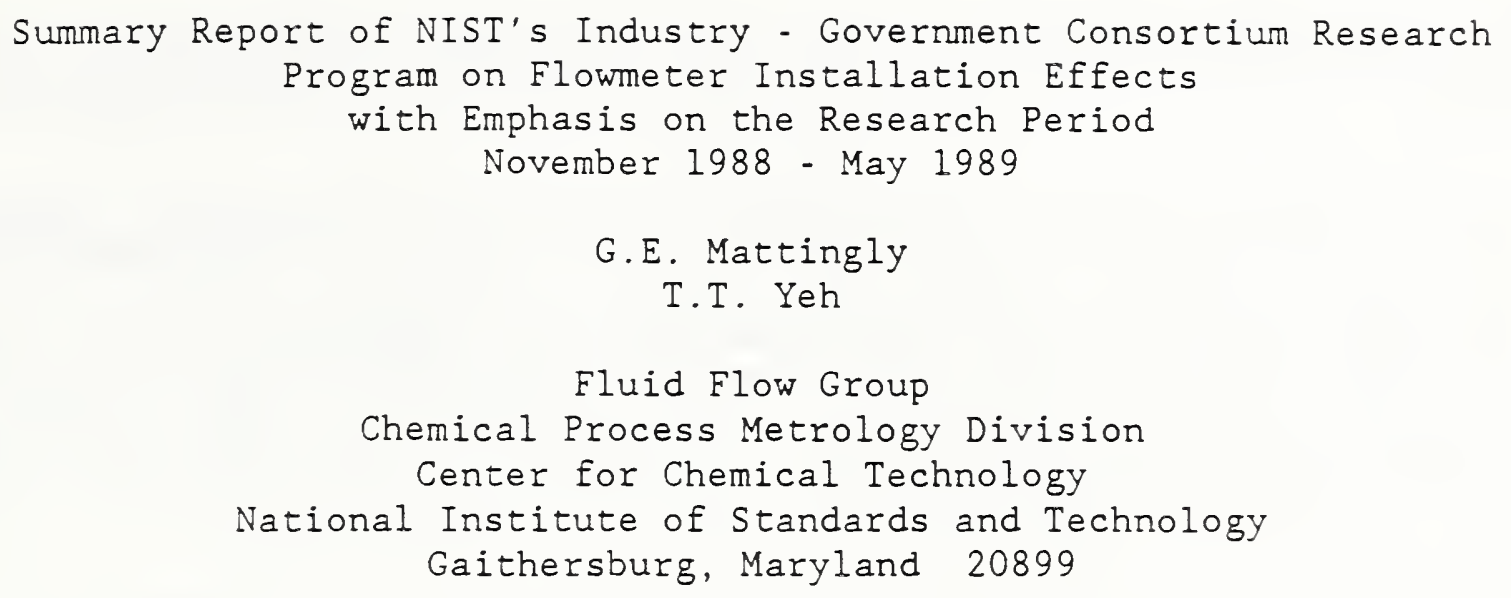

\section{ABSTRACT}

This report presents results produced in a consortium-sponsored research program on flowmeter installation effects. This project is a collaborative one that has been underway for four years; it is supported by an industry-government consortium that meets twice yearly to review and discuss results and to plan subsequent phases of the work. This report contains the results and conclusions of the recent meeting of this consortium at NIST-Gaithersburg, MD in May 1989.

The objective of this research program is to produce improved flowmeter performance when meters are installed in non-ideal conditions. This objective is being attained via a strategy to (a) measure, understand, and quantify the salient features of non-ideal pipe flows from such pipeline elements as elbows, reducers, valves, flow conditioners, etc. or combinations of these, (b) to correlate meter-factor shifts for selected types of flowmeters, relative to the features of these non-ideal pipe flows so as to be able to predict meter performance accurately in non-ideal installations, and (c) disseminate the resulting technology through appropriate channels such as publishing our results in pertinent journals and upgrading paper standards for flow measurement.

Specific results included in this report for the pipe flow from a conventional, long radius elbow followed by a conventional tube bundle are:

1. the distributions of the mean and the turbulence velocities in the axial and vertical directions both up-and downstream of the tube bundle,

2. the performance of selected types of flowmeters installed downstream of this elbow and tube bundle arrangement, and

3. the demonstration that satisfactory performance for the selected meters can be predicted using the research results of this study.

\section{INTRODUCTION}

The increasing scarcity of fluid resources and the rising value of fluid products are placing new emphases on improved fluid measurements. Improvements are sought from many starting points. Meters are being retrofitted into fluid systems that were not designed for them. This invariably means the flowmeters are being inserted in non-ideal installation conditions. Increased accuracy levels are 
desired for installed metering systems - either by upgrading the flow conditions that enter the meter or by replacing the device itself and/or its auxiliary components.

Flow conditioning devices of one geometry or another are frequently recommended in metering standards for improving flowmeter performance when installation conditions are not ideal. However, the pipeflows generated by these devices have to be considered in light of the flowmeter installed downstream and the pertinent parameters that control pipeflow phenomena and the parameters that influence the performance of the particular meter. It will be shown in what follows that certain flow conditioner installations can produce serious deviations from the performance of specific meters in ideal installation conditions.

The industry-government consortium research program on flowmeter installation effects that is currently underway at NIST is designed to help improve fluid metering performance when installation conditions are not ideal. The design of the program is to produce a basic understanding of the flow phenomena that are produced in non-ideal pipe flows and to quantify these phenomena. When these phenomena and their quantified characteristics are correlated with the performance of specific types of meters, it should be feasible to predict and achieve satisfactory measurements in non-ideal meter installations. The success of this approach has been demonstrated using several different types of flowmeters installed downstream of several different pipe elbow configurations.

The experimental research program is based upon the measurements of pipe flows from selected piping configurations using laser Doppler velocimetry (LDV). [1. 4]* Selections of piping configurations and pipeline elements such as flow conditioners are done by vote of the consortium members; one or two such configurations can be done in one year.

The LDV techniques that have been and are being applied to determine pipe flows can also be used to measure the effects of other pipeline elements - valves, flow conditioning elements (for fluid velocity or pulsations, etc.), mixing devices, generic flowmeter geometries - or combinations of these. The resulting understanding provides the basis for improving the effectiveness of these devices and, in turn, the performances of flowmeters installed downstream and, thus, for increasing the productivity of the continuous processes which depend upon them. $[4-8]$

In the present study, the fluid is water and the piping is 2 inch diameter ( 52.5 $\mathrm{mm}$ ), smooth, stainless steel. The relative roughness of this pipe has been measured with a profilometer to indicate a value of $0.006 \%$. Diametral Reynolds numbers range up to $10^{5}$. According to the concepts of dynamic similitude, the results of the present research program should predict a range of other flows both liquids and gases - when pertinent parameters match those in our experiments.

When the performance of flowmeters - similar to or different from those selected is determined by calibration tests, meter performance can be correlated to pipe

* Square bracketed integers refer to references given below. 
flow parameters. When this is achieved - by flowmeter manufacturers or users alike - it should then be possible to predict satisfactory metering performance for these meters in similar non-ideal installations.

\section{EXPERIMENTAL RESULTS:}

In what follows, results are presented for the pipe flow from a single conventional, long-radius elbow oriented vertically so as to turn a fully developed, equilibrated, turbulent pipe flow into the horizontal pipe in which a conventional tube bundle is installed. The arrangement is sketched in figure 1 , where all dimensions are given in pipe diameters. The flow measurements were made both upstream and downstream of this tube bundle. The tube bundle is sketched in figure 2. This tube bundle is the concentric type as contrasted with the row type. It's dimensions are given in the figure in millimeters. This tube bundle is a scaled version of the tube bundle conventionally used in the U.S. in large size pipes. The experimental results from this phase of the research program are:

1. Mean Velocity Measurements. The right hand coordinate system used in what follows has an origin at the pipe centerline at the exit plane of the elbow. The positive $Z$ direction is downstream; the positive $Y$ direction is upward; the $X$ direction is therefore to the right looking upstream. The mean velocities in the $X, Y$, and $Z$ directions are $U, V$, and $W$, respectively; the corresponding turbulence velocities, are $u^{\prime}, v^{\prime}$, and $w^{\prime}$. A sketch is given in figure 3 .

In the legends on the figures that will show our measurement results, a letter convention will be used to indicate the piping configuration being studied. The letter "L" is used to indicate that long-radius elbows are used (radius of centerline curvature is 1.5 times the inside pipe diameter), and when this $L$ is followed by $-Y$, this means the inlet pipe length has flow directed in the negative $Y$ direction of the coordinate system described above. Thus, L-Y indicates that a single elbow receives a downwardly directed pipe flow and turns it horizontally into the positive $Z$ direction. The letter convention L-Y, FCI means that our elbow is followed by the tube bundle installed as shown in figure 1 .

All quantities are nondimensionalized using the bulk average pipe-flow velocity to normalize all velocities and using the pipe inside diameter to normalize lengths. For the single elbow configuration followed by the tube bundle, the distributions of the mean components of the streamwise velocity along the horizontal and vertical diameters for locations both upstream and downstream of the tube bundle are plotted in Figure $4(\mathrm{a})$ and (b). The diametral Reynolds number is $10^{5}$. The dashed line in both figures is the corresponding power law profile for these conditions i.e., smooth pipe; the exponent for this profile is $n=7$. The centerline slope discontinuity associated with the power law distribution has been smoothed. The profile at the center of the pipe between \pm 0.1 is obtained from the third order polynomial based upon the values at \pm 0.1 and \pm 0.15 .

The measured results show the symmetry about the pipe centerline of the streamwise velocity profile along the horizontal diameter. The deviations from the power law profile at the location $Z=2.7$ which is upstream of the tube bundle indicate that the slow core of this profile is about $40 \%$ slower than the bulk velocity. 
Downstream of the tube bundle, the profile at location $Z=6.2$ clearly shows the jetting effects of the flows exiting the small tubes. These jets interact with each other to produce high levels of turbulence in the wake of the tube bundle. With further downstream distance these deviations diminish. Near the pipewall there are layers of fluid which move faster than the power law values thereby indicating that these pipeflows are flatter than the power law profiles at and beyond the location $Z=12.7$.

Figure 4(b) shows similar deviations in the center core of this pipeflow and the measured profile along the vertical diameter is not symmetrical about the center of the pipe. Upstream of the tube bundle, the fast layers of fluid near the bottom of the pipe are some $30 \%$ of the bulk flow faster than the power law values. Downstream of the tube bundle these deviations are decreased markedly and the jetting effects are evident. At the $Z=12.7$ location, the profile has qualitatively, the general features the form of the profile entering the tube bundle.

Figures 5(a) and (b) present the streamwise velocity profiles along horizontal and vertical diameters, respectively, for diametral Reynolds number of $10^{4}$. As before, the dashed line shows the corresponding power law profile, for which $n=$ 6.3. For the profile along the horizontal diameter, deviations similar to those shown in figure 4 (a) are noted for all three locations. Similar results are found for the profiles along the vertical diameter.

Figures 6(a) and (b) present the vertical velocity profiles along horizontal and vertical diameters, respectively, for diametral Reynolds number of $10^{5}$. Here, the fully developed pipeflow is shown by the dashed line which is everywhere zero. The distributions shown in figure $6(\mathrm{a})$ indicate that at $Z=2.7$, upstream of the tube bundle, the upward vertical velocities near the pipewall are $15 \%$ of the bulk velocity. At the centerline; the downward velocity is almost $25 \%$ of the bulk velocity. Downstream of the tube bundle, these distributions change markedly. At location $Z=6.2$, it is found that vertical velocities reach only about $3 \%$ of the bulk velocity downstream of tube outlets. These reduced velocities result from the tube diameter to length ratio being about 0.1 . It is therefore seen that the tube bundle does not completely eliminate transverse (i.e., swirl) velocities; it simply reduces them in accord with the fluid flow parameters and the geometry of the tube bundle.

Figure $6(\mathrm{~b})$ shows that the measured vertical velocity along the vertical diameter is negative everywhere. Again, the dashed line pertains to the corresponding fully developed profile. Just above the pipe centerline at $Z=2.7$ the magnitude of the negative velocity is $25 \%$ of the bulk velocity. This distribution is changed by the effects of the tube bundle as shown by the results at $Z=6.2$ and 12.7 .

Figures $7(a)$ and (b) show the vertical velocity distributions along horizontal and vertical diameters for dimetral Reynolds number $10^{4}$. The deviations from the dashed (fully developed) profile are smaller than their counterparts in figures $6(a)$ and (b). The effects of the tube bundle are given by the profiles at $Z=$ 6.2. By the location $Z=12.7$, the vertical velocity is essentially zero everywhere. 
Some early conclusions that can be drawn from figures 4 - 7 are that several Reynolds number effects can be noted. The first is that the initial secondary flows produced by this elbow in these pipeflows have greater velocities at the higher Reynolds number. Secondly, these secondary flows are modified significantly by the tube bundle. The axial velocity distributions immediately downstream of the tube bundle show jetting effects from the flows exiting the tubes. With further distance downstream the axial velocity profiles are found to resemble qualitatively the profile features which entered the tube bundle. The vertical velocity distributions were suppressed by the tube bundle except for small peaks at the outlets of the tubes. The decay of these secondary flow effects is expected to be more rapid for the lower Reynolds number condition of $10^{4}$ and less rapid for the higher Reynolds number condition of $10^{5}$. As well, the decay of such secondary flows should be more rapid when the pipe wall roughness is greater than the smooth wall pipe used in the present study where roughness was measured to be 125 microinches or 0.00006 relative roughness, as described above.

2. Turbulence Measurements. Turbulent velocity components in both the streamise and vertical directions were measured traversing both horizontal and vertical diameters. Results are normalized using the bulk average velocity and comparisons are made with results previously available.

Figures $8(a)$ and (b) present results for the streamwise and vertical components of the turbulent velocity at successive streamwise locations for diametral Reynolds number $10^{5}$. Given also in these figures by the dashed lines are the distributions measured by Laufer [9] in an airflow at Reynolds number $4 \times 10^{5}$. These results for the turbulence entering the tube bundle show both qualitative and quantitative differences from Laufer's results. This is, of course, due to the secondary flows produced by the elbow. Downstream of the tube bundle, the turbulence is found to be increased significantly by the effects of the tube bundle. The turbulence here is both qualitatively and quantitatively different from the distributions measured by Laufer. Because of these differences the performance of flow meters installed in these locations can be expected to be different from installations that are ideal.

3. Skew Angle Distributions. The secondary flow measurements described above can be characterized and parameterized in many ways. To use the resulting parameters to predict the performance of flowmeters in these non-ideal flows, the operation principles of the flowmeter need to be considered. For example, if the meter is sensitive to angular momentum or vorticity, then the parameters describing these features should be explored. On the other hand, if the meter is sensitive to turbulence effects, then turbulence parameters should be examined. The next step in the process of devising a scheme to predict the performance of the specific meter in these non-ideal pipe flows is to correlate the developed parameters with calibration data for the specific meter in these flows. Then, using the parameter for which the correlation is the most successful, the performance of this meter should then be predictable.

To quantify the time averaged swirl features of these pipe flows, a range of parameters have been formulated.[1-2] The present results will be used to determine the local value of the skew angle which we define as:

Skew Angle $=\tan ^{-1}(\mathrm{~V} / \mathrm{W})$. 
Figures $9(a)$ and (b) show results for skew angle distributions along horizontal and vertical diameters for $\operatorname{Re}_{\mathrm{D}}=10^{5}$. These results show quantitatively how this tube bundle suppresses transverse velocities.

4. Comparisons of Results With and Without the Tube Bundle. Figures 10(a) and (b) present results for the mean axial and vertical velocity components along the horizontal diameter with and without the tube bundle for $R_{D}=10^{5}$. These results show that the presence of the tube bundle does not significantly alter the secondary flow pattern being generated by the single elbow upstream in these flow conditions. In figure $10(\mathrm{~b})$, the difference between the two distributions is more of a shift in the origin due to LDV misalignment than it is a vertical displacement of the velocities.

Figure $11(a)$ and (b) present results for the mean axial velocity distributions along the horizontal and vertical diameters with and without the tube bundle for $R e_{D}=10^{5}$ at the downstream location designated by $Z=6.2$.

These results in figure $11(a)$ show by comparison the effects of the tubes in the bundle on the mean velocity profiles. The peaks in the profile downstream of the tube bundle indicate the higher velocities in the flows out of the individual tubes or out of the regions between tubes. The frictional drag produced by the tube walls is evident from the minima in the profile just downstream of the tube bundle. It is apparent that the presence of the tube bundle does not produce the ideal profile indicated by the dashed line. In figure 1l(b) the comparison of the profiles without and with the tube bundle shows that the vertical velocity profile is radically altered by this flow conditioner. The less distinct peaks in figure 11(a) located nearer the pipe walls are probably due to the flows from cavities between adjacent tubes as observed along a horizontal diameter in figure 2 .

Figures $12(\mathrm{a}-\mathrm{c})$ present results at $Z=2.7$ and 6.2 for the vertical velocity components for $\operatorname{Re}=10^{5}$ with and without the tube bundle. Again, it is noted that in figure $12(\mathrm{~b})$ the tube bundle drastically alters the vertical velocity distribution due to the effects of the tubes. Both of the profiles downstream of the tube bundle closely approximate the ideal profiles which are shown by the dashed lines to be zero.

Figures 13(a) and 13(b) present the profiles along the vertical diameter of the streamwise and vertical components of the turbulent velocity at the $Z=6.2$ downstream station with and without the tube bundle. Comparisons of these profiles clearly shows the high levels of turbulence that are generated by this device. The dashed profiles in these figures present the data measured by Laufer. It is noted that significant qualitative and quantitative differences prevail among the three profiles. In both of these figures, the individual peaks or the regions of high turbulence levels in the profiles behind the tube bundle are apparently due to the dynamic fluid interactions between the jetting flows from adjacent tubes.

When swirl angles are computed from the mean velocity profile, the distributions shown in figures $14(\mathrm{a})$ and $14(\mathrm{~b})$ are obtained. As noted above, the swirl-angle profiles along the horizontal and vertical diameters show that the swirl has been 
reduced by the tube bundle to less than about $23^{\circ}$. According to ISO 5167 [10], this level of swirl angle is low enough that orifice meters should be expected to have discharge coefficients within $\pm 0.5 \%$ of the coefficients obtained in ideal orifice-installation conditions. However, in what follows the orifice meter performance in these low-swirling flows will be shown to be significantly different from the expected ideal performance results.

\section{Flowmeter Results}

a.) Orifice Meters When orifice meters are calibrated in different locations downstream of the single elbow, the results are considered in terms of shifts relative to the average discharge coefficient from ideal installation conditions. By "ideal" in the present research program is meant the orifice discharge coefficients obtained when approximately 210 diameters of straight, constant diameter piping precedes the orifice meter. In figures $15(\mathrm{a})-(\mathrm{c})$ the orifice meter discharge coefficient versus Reynolds number results are shown for beta ratios (orifice hole-to-inner pipe diameter) of $0.363,0.50$, and 0.75 , respectively. These results were obtained for the single elbow oriented in a vertical plane; the orifice meter was located in the horizontal pipe downstream of the elbow the distance $Z$ in diameters given in the legend of each figure. The orifice taps were the flange-type and were oriented along the side of the horizontal pipe.

The results in figures $15(\mathrm{a})-(\mathrm{c})$ show that these orifice meters have, at each flowrate, discharge coefficients that are lower than the respective value for the ideal installation condition. Note the different ordinate scales for the three figures. The reduction of the discharge coefficient is lowest for the installation nearest the elbow, and this reduction is found to decrease as the orifice is placed further from the elbow. The reduction of the discharge coefficient is also dependent upon the beta ratio with the largest reduction approximately $5 \%$ for the case of this meter installed 2.9 diameters downstream from the exit plane of the elbow.

For beta $=0.363$ at the location $Z=20.3$, the discharge coefficient distribution closely approximates that for the ideal condition. For the other beta ratios, this location produces larger differences as compared to the ideal case, and those differences increase with beta ratio. More testing would be required for these meters to specify precisely the way the ideal installation performance is approached as the distance between elbow and orifice is increased.

b.) Turbine-type Meters. When a specific turbine-type flow meter is calibrated in different locations downstream of this elbow, the results are as shown in figure 16 where results are plotted in per cent relative to the average meter factor obtained in the ideal conditions. This meter normally spins counterclockwise, looking downstream. These results indicate that the pipeflow from this elbow tend to reduce the meter factor for this meter. This trend is largest for meter positions nearest the elbow; the effects on this meter appear to be dissipated at and beyond the twenty-diameter point. It seems apparent that turbine wheels which essentially cover the cross-sectional area of the pipe tend to cancel the effect of the counter rotating eddies produced by these elbow conditions. For the orifice meter discussed above this tendency is not apparent. 
c.) Orifice Meter and Tube Bundle Conditioner. When orifice-type flow meters are calibrated downstream of the elbow and tube bundle arrangement shown in figure 1 , the results obtained are presented for beta ratios $0.363,0.50$, and 0.75 in figures $17(a)-(c)$, respectively. Note the ordinate scales. The quantity $C$ refers to the distance in diameters between the exit plane of the tube bundle and the orifice plate. As before, the discharge coefficients are shown as percentages relative to the average discharge coefficient for the ideal installation. The tapping arrangement and orientation relative to the elbow is the same as before.

The results in figures $17(a)-(c)$ indicate that orifice discharge coefficients are less than the corresponding ideal values, for all of these beta ratios, when the meter is about thirteen diameters from the exit plane of the tube bundle. For orifice meter positions beyond the thirteen diameter installation position these meters have discharge coefficients larger than for the ideal condition. This overshoot condition is smaller than the reduction in discharge found for the nearest location tested.

Figures $17(a)-(c)$ show that at location, $C=48.1$ (i.e., $Z=53.8$ ) the discharge coefficients for these orifice conditions closely approximate those for the ideal installation conditions. It is concluded therefore that the use of the tube bundle flow conditioner to produce ideal orifice meter performance may require detailed distributions to be known for the pipeflow or considerable lengths (i.e., 50-60 diameters) of straight, constant diameter between the tube bundle and the meter. It is further concluded that if one decides to insert the orifice meter at the cross-over point at $\mathrm{C}=13$ in order to obtain ideal orifice performance, this installation can be sensitive to parameters such as Reynolds number, relation roughness, and the particular pipeflow distributions.

To explain the negative shift in orifice discharge coefficient, one can analyze figures $4(\mathrm{a})$ and 5(a). Here, the mean axial velocity distribution across the horizontal diameter at $Z=12.7$ (this corresponds to the position $C=7.0$ ) is quite flat compared to that for the ideal power law profile. This situation can produce elevated pressure regions at the upstream tap location thereby lowering the discharge coefficient. [4] With increasing downstream distance, the pipeflow profiles evolve toward the ideal distribution and accordingly the reductions in the discharge coefficient diminish. This is shown in figure 18 for these three beta ratios. Further downstream, the orifice discharge coefficients are found to equal and exceed the ideal values, as shown in figure 19. With only limited velocity measurements, at present, we are not yet able to explain the reasons for this overshoot phenomena associated with the tube bundle.

Direct comparisons of these orifice meter results - versus the axial position of the meter - with and without the tube bundle - are plotted in figures 20(a)-(c). In these, the symbol denotes the average value of the percentage change of the discharge coefficient over the flowrates tested. The error bars denote the range \pm one standard deviation of the discharge coefficient percentages for that particular installation. The ordinate scales are different for different beta ratios.

When these orifice results for beta $=0.5$ and 0.75 are compared to those from other investigations, similar trends are noted even though the Reynolds numbers and relative roughnesses are undoubtedly different from those of the present 
study, see [11]. This is shown in figures 21(a) and (b). The orifice tapping standards were the same for all these results namely flange taps. Where data was available, error bars are drawn to quantify ranges for ordinate values. It is concluded that trends described above are corroborated by others.

d.) Turbine-type Meter and Tube-Bundle Conditioner: When the turbine-type flowmeter is calibrated downstream of the tube bundle in the arrangement shown in figure 1 , the results obtained are shown - as percentages relative to the ideal performance - in figure 22. Here, it is noted that when this meter is installed only short distances downstream from this tube bundle, the meter factor is reduced relative to the ideal results. However, in contrast with the orifice meter performance described above, this turbine-type meter does not exhibit the performance over-shoot phenomena shown in figures 19-21.

Figure 23 shows the performance characteristics of this turbine-type meter relative to the ideal versus axial position with and without the tube bundle. In this graph, the symbol denotes the average value of the percentage change for the meter factor change relative to the ideal value - taken over the range of flowrates tested - at the respective axial position; $Z$. The error bars delineate \pm one standard deviation of the meter factor percentages obtained over the flowrate range tested.

Conclusions: Based upon our laser velocity surveys downstream of the single elbow and up - and downstream the tube bundle, it is concluded that:

1.) The presence of the tube bundle does not significantly change the pipeflow which exits the elbow from that measured in the absence of the tube bundle,

2.) The tube bundle does significantly change both the mean and the turbulent velocity distributions measured downstream of it and these deviations diminish with distance,

3.) The tube bundle does significantly reduce swirl to very low levels through the effects of the tubes on the azimuthal and radial components of the mean pipeflow. The tube bundle produces pronounced jetting effects due to the flows out of the individual tubes.

4.) The interactions between the jetting flows from adjacent tubes appears to generate high levels of turbulence,

5.) The distributions of both mean and turbulent velocities result from the non-uniform porosity of this tube bundle arrangement,

The tube-bundle-conditioned flows appear to perturb significantly the performance of several types of flowmeters - i.e., orifice and turbine. Specific conclusions are:

1.) While both of these types of meters have their performance characteristics (orifice discharge coefficients and turbine meter factors in pulses per volume) reduced by the secondary flows produced by the single elbow, the effects of the tube bundle increase the sizes of these reductions for the turbine meter and decrease the reductions for the orifice meter. 
2.) The distributions of these reductions with axial distance from the tube bundle occur differently from those in the absence of the tube bundle,

3.) With the tube bundle, the performance of the orifice-type meters tested shows that, for meters downstream of the tube bundle and close to it, discharge coefficient are reduced relative to those for ideal installation conditions,

4.) These reductions in discharge coefficient decrease markedly with orifice meter position downstream from the tube bundle and then cross zero to then give coefficients larger than the ideal values,

5.) With considerable distance downstream of the tube bundle - i.e., 45-55 diameters, the orifice meters perform as in ideal conditions.

6.) The orifice performance characteristics determined in the present program corroborate those from several others - even where Reynolds numbers and relative roughnesses are different. 


\section{REFERENCES}

1. Mattingly, G.E. and Yeh, T.T. NIST's Industry-Government Consortium Research Program on Flowmeter Installation Effects: Report of Results for the Research Period June - December 1987. NISTIR-88-3898. Sept. 1988.

2. Mattingly, G.E., and Yeh, T.T., NIST's Industry-Government Consortium Research Program on Flowmeter Installation Effects: Report of Results for the Research Period Jan. 1988 - Oct. 1988. NISTIR-89

3. Mattingly, G.E., Yeh, T.T., Robertson, B. and Kothari, K., NBS Research on In-Situ Flowmeter Installations, Procs. AGA Distribution and Transmission Confr. Las Vegas NV, May 1987.

4. Mattingly, G.E., Spencer, E.A., and Kline, M. Workshop on Fundamental Research Issues in Orifice Metering, GRI Rept. 84/0190, Sept. 1984.

5. Mottram, R.C. and Hutton, S.P., Installation Effects: Turbine and Vortex Flowmeters, Rept. No. 3 Flow Measurement and Instrumentation Consortium, Cranfield Inst. of Tech., Bedfordshire, U.K. Dec. 1987.

6. Yeh, T.T. and Mattingly, G.E. Mixing Motions Produced by Pipe Elbows, Procs. AIChE Winter Annual Meeting. Wash. D.C., Dec. 1988.

7. Norman, R.S., Mattingly, G.E., and McFaddin, S.E., The Decay of Swirl in Pipes, 1989 International Gas Research Confr., Tokyo, JAPAN, Nov. 1989.

8. Mottram, R.C. and Rawat, M.S., Attenuation Effects of Pipe Roughness on Swirl and The Implications for Flowmeter Installation. International Symposium on Fluid Flow Measurement, American Gas Association (1986).

9. Laufer, J., The Structure of Turbulence in Fully Developed Pipe Flow, NBS Rept 1974, Sept 1952. Alternatively see Hinze, J.0., Turbulence, McGrawHill, New York (1959) (Laufer's data in chapter 7).

10. ISO Standard 5167 - Measurement of Fluid Flow by Means of Orifice Plates Nozzles, and Venturi Tubes Inserted in Circular Cross-Section Conduits Running Tall, Geneva, Switz., 1980.

11. Smith, D.J.M., The Effects of Flow Structures on Orifice Plates in Good Flow Conditions, Procs: Flow Measurement in the Mid 1980's, Nat'l Engr. Laboratory Conference, June 1986. 


\section{APPENDIX 1}

\section{NIST INDUSTRY-GOVERNMENT CONSORTIUM MEMBERSHIP}

As of the 1989 research period, the NIST Industry-Government Consortium Research Program on Flowmeter Installation Effects included the following members, in alphabetical order:

1. Ametek-McCrometer

2. Chevron Oil

3. Dow Chemical Co.

4. E.I. DuPont de Nemours

5. Ford Motor Co.

6. Gas Research Institute

7. Gas Unie (The Netherlands)

8. Instrument Testing Service

9. ITT Barton

10. Kimmon Mfg. Led. (Japan)

11. NIST-Boulder

12. Rockwell International

13. Rosemount 

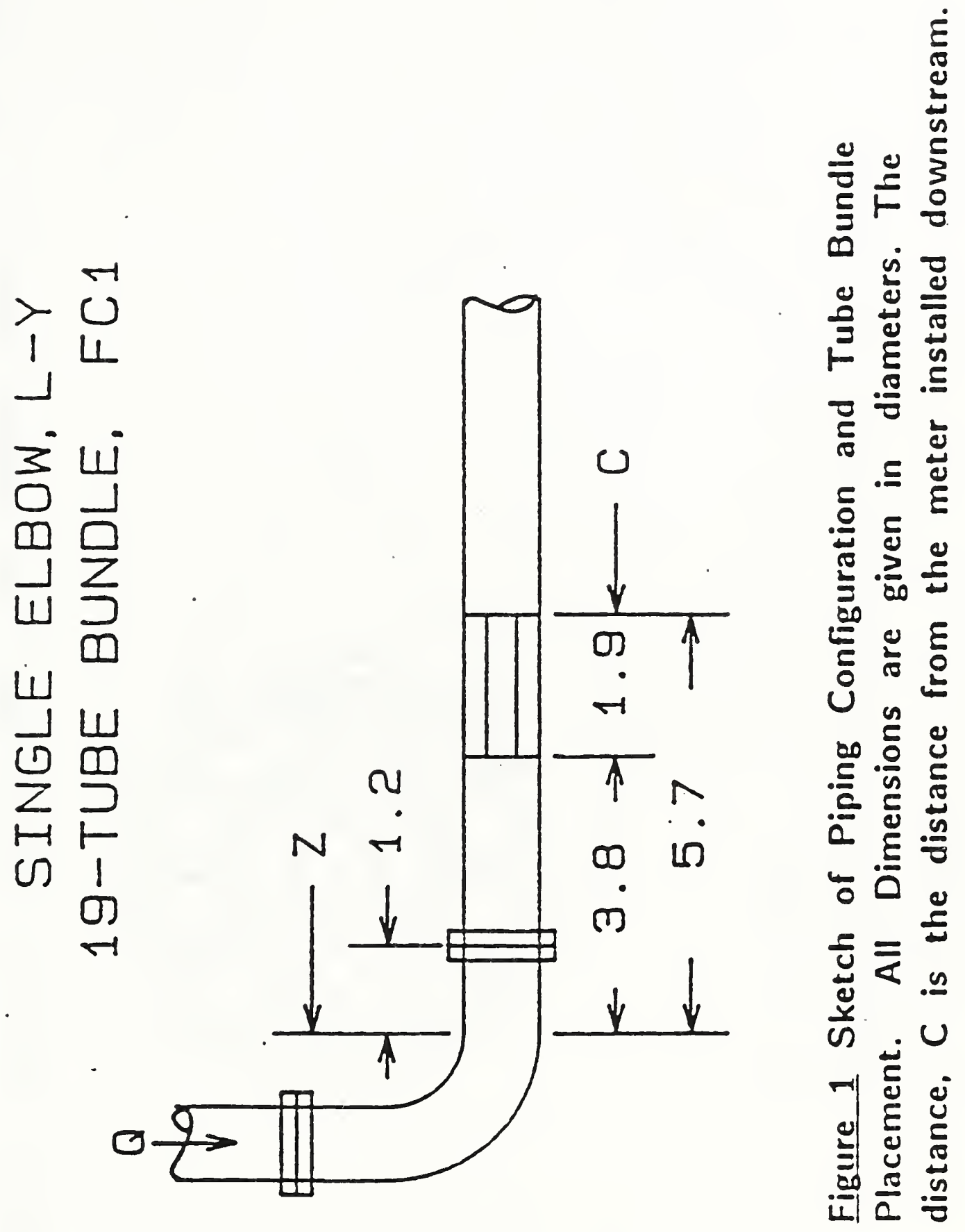


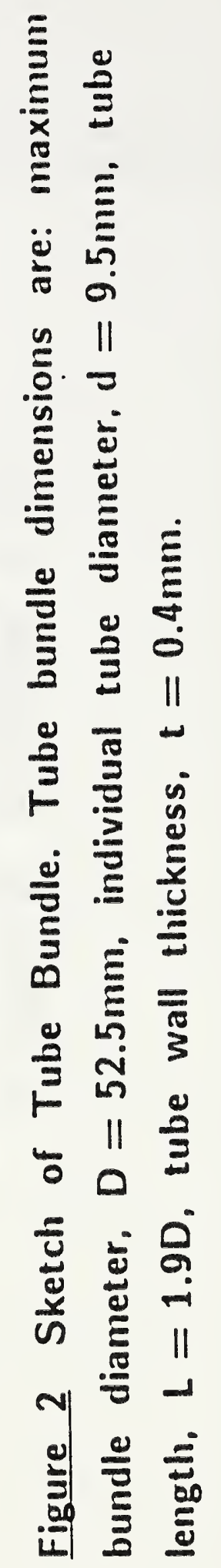




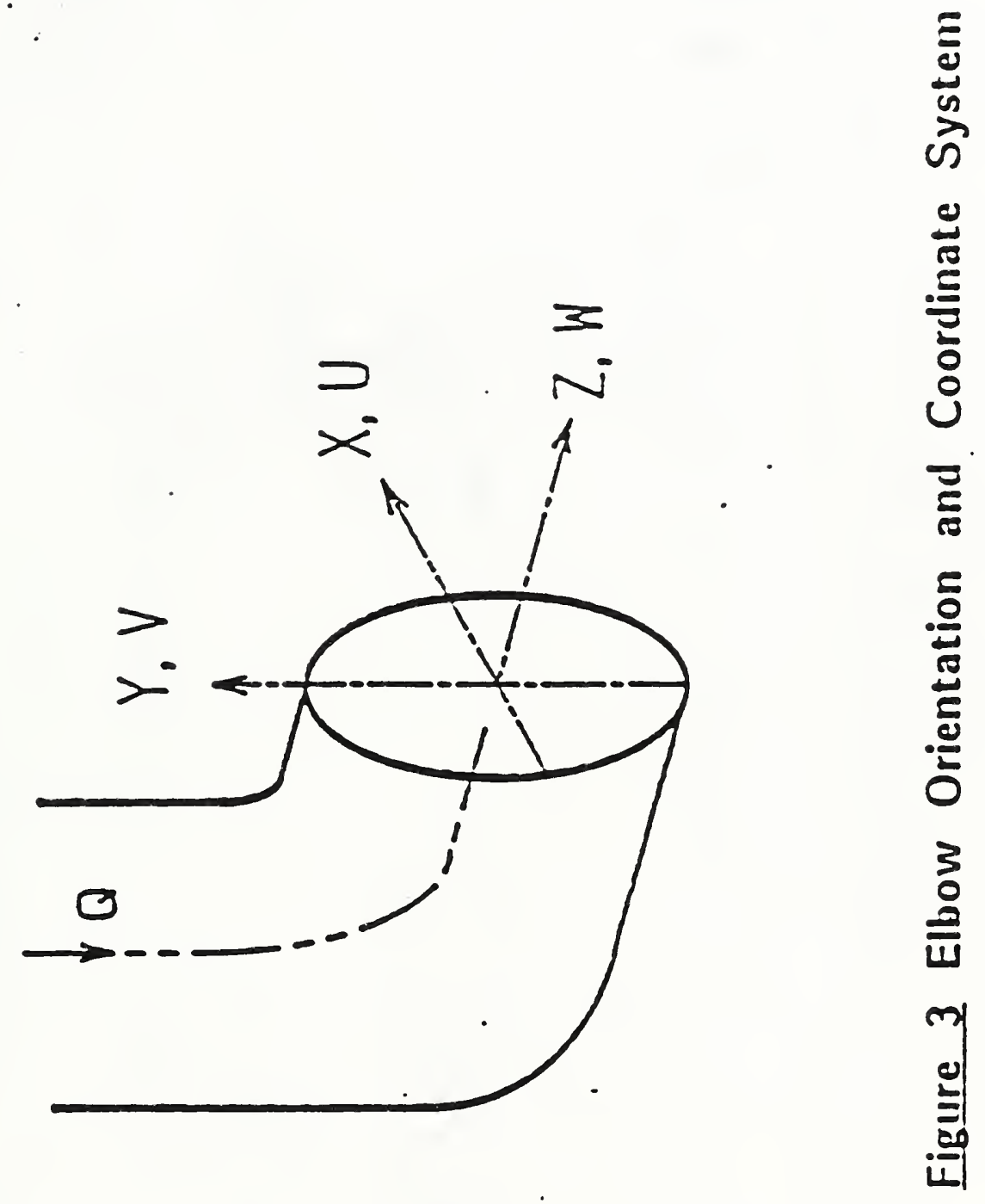




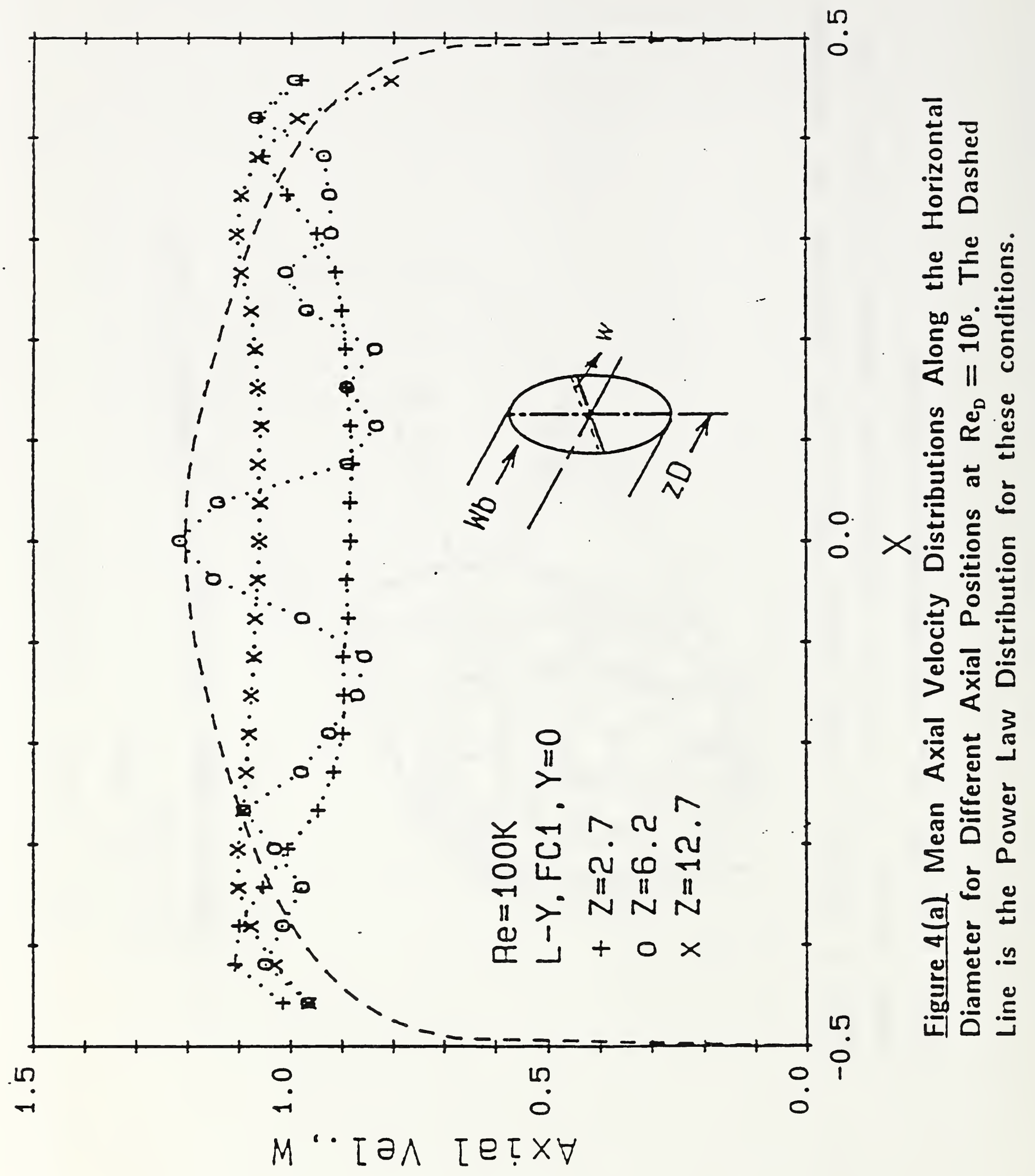




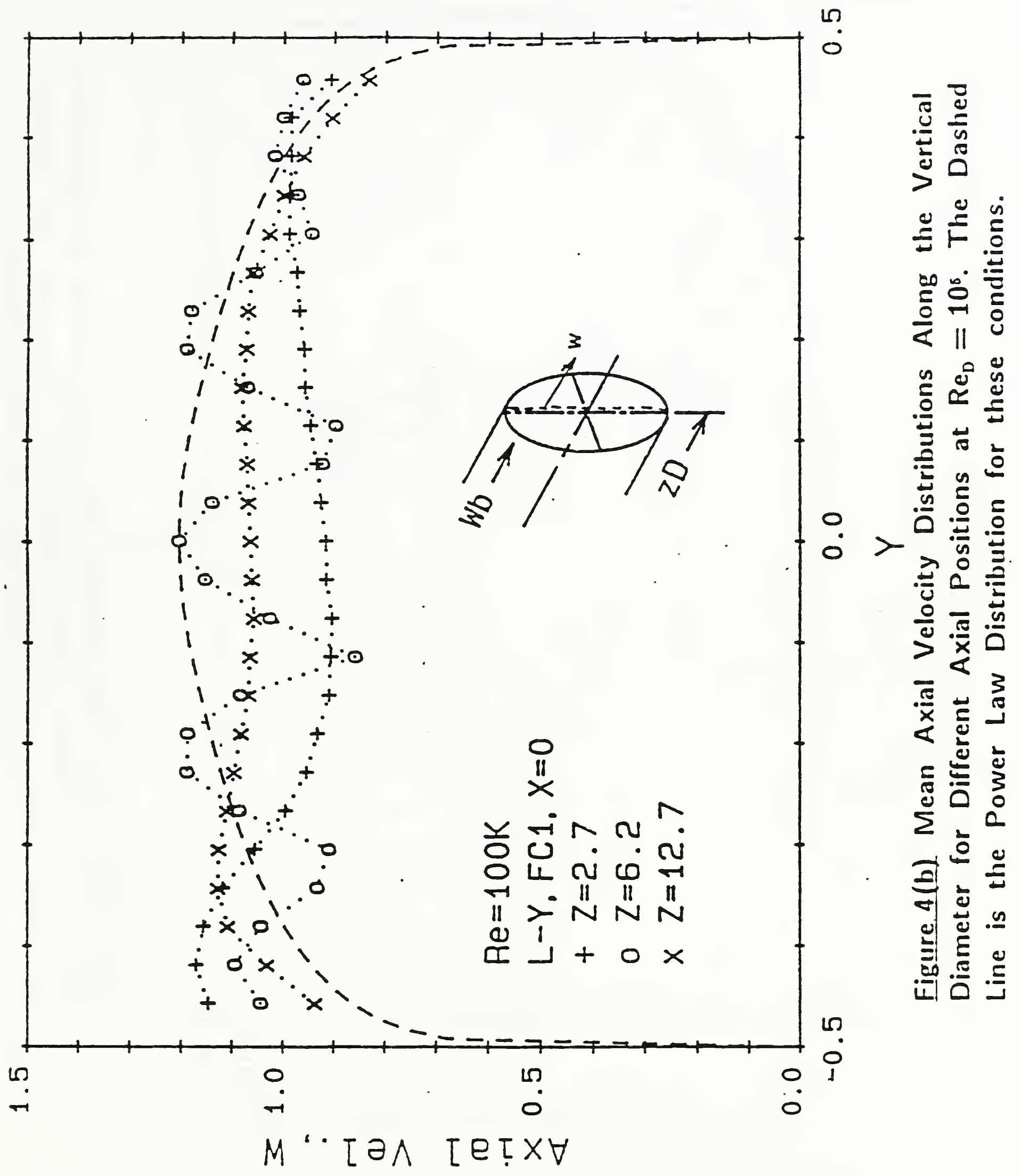




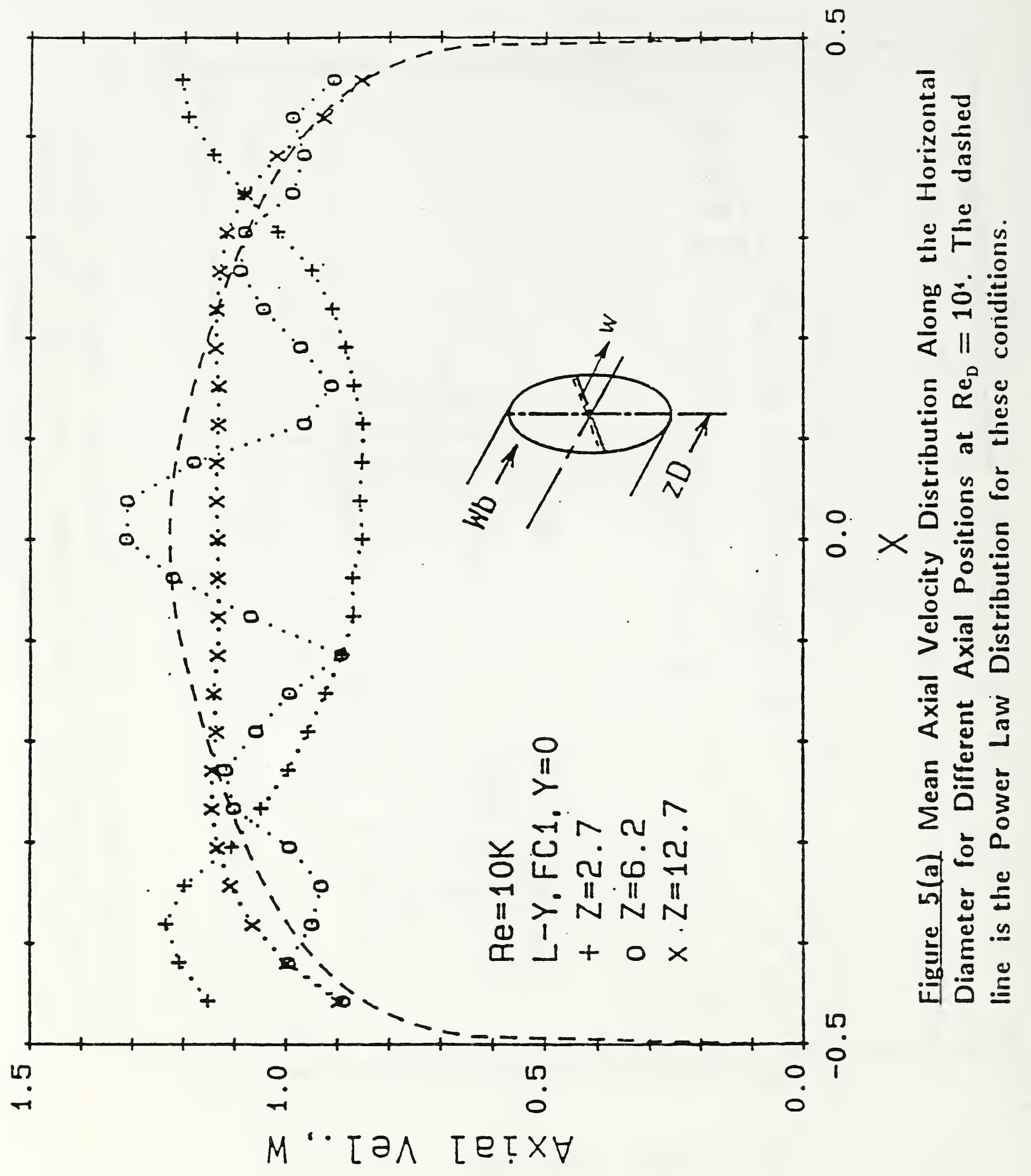




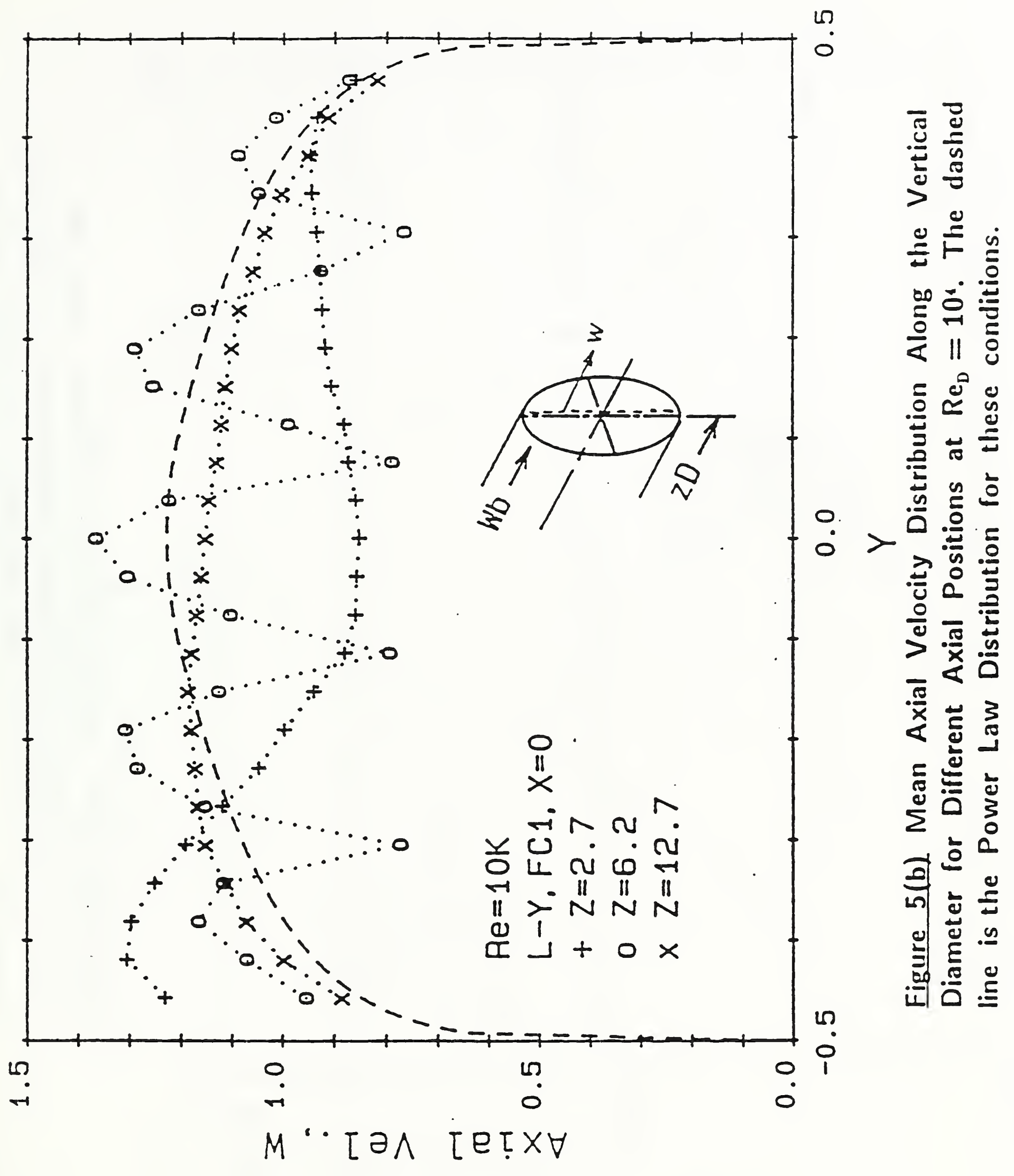




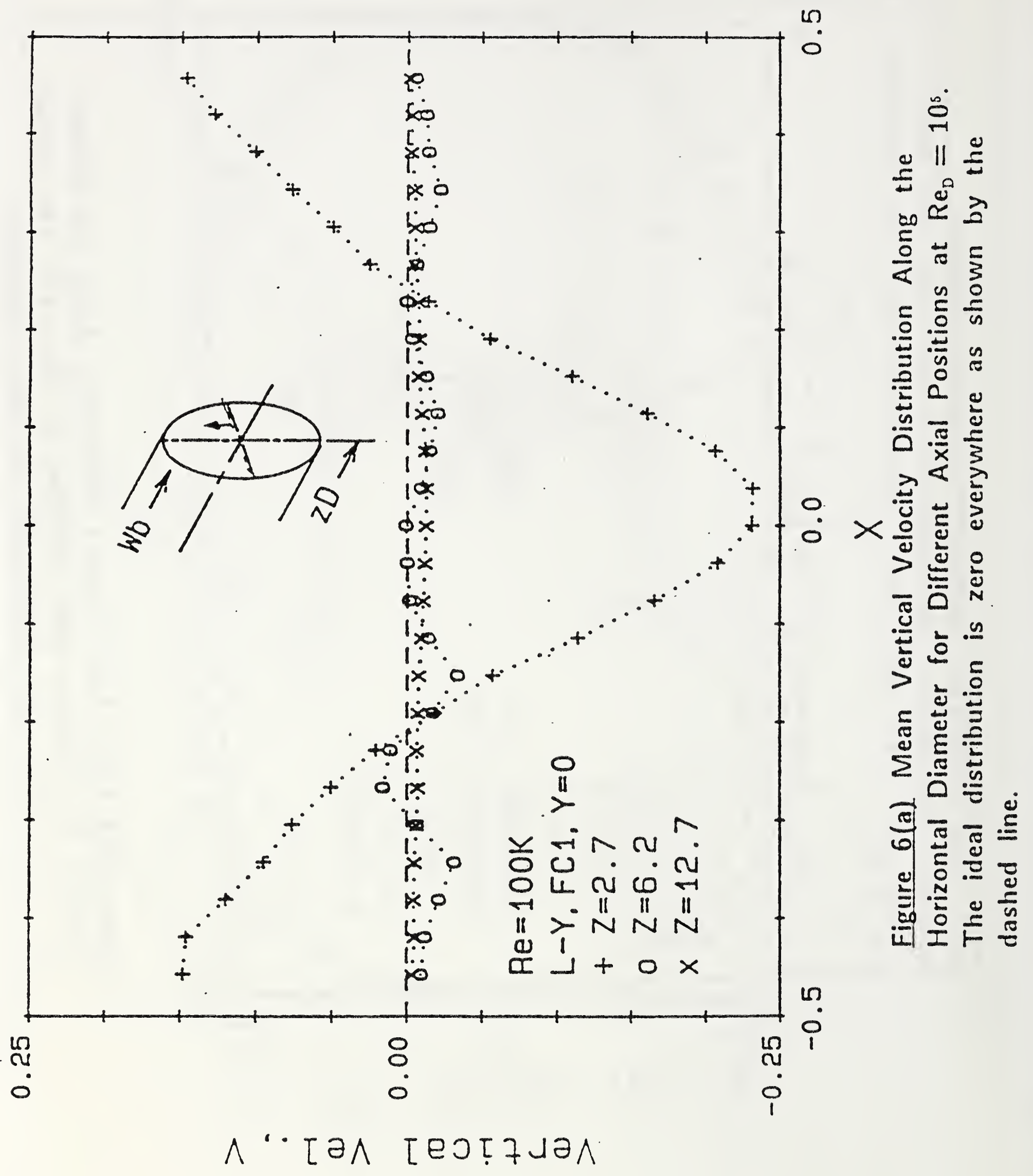




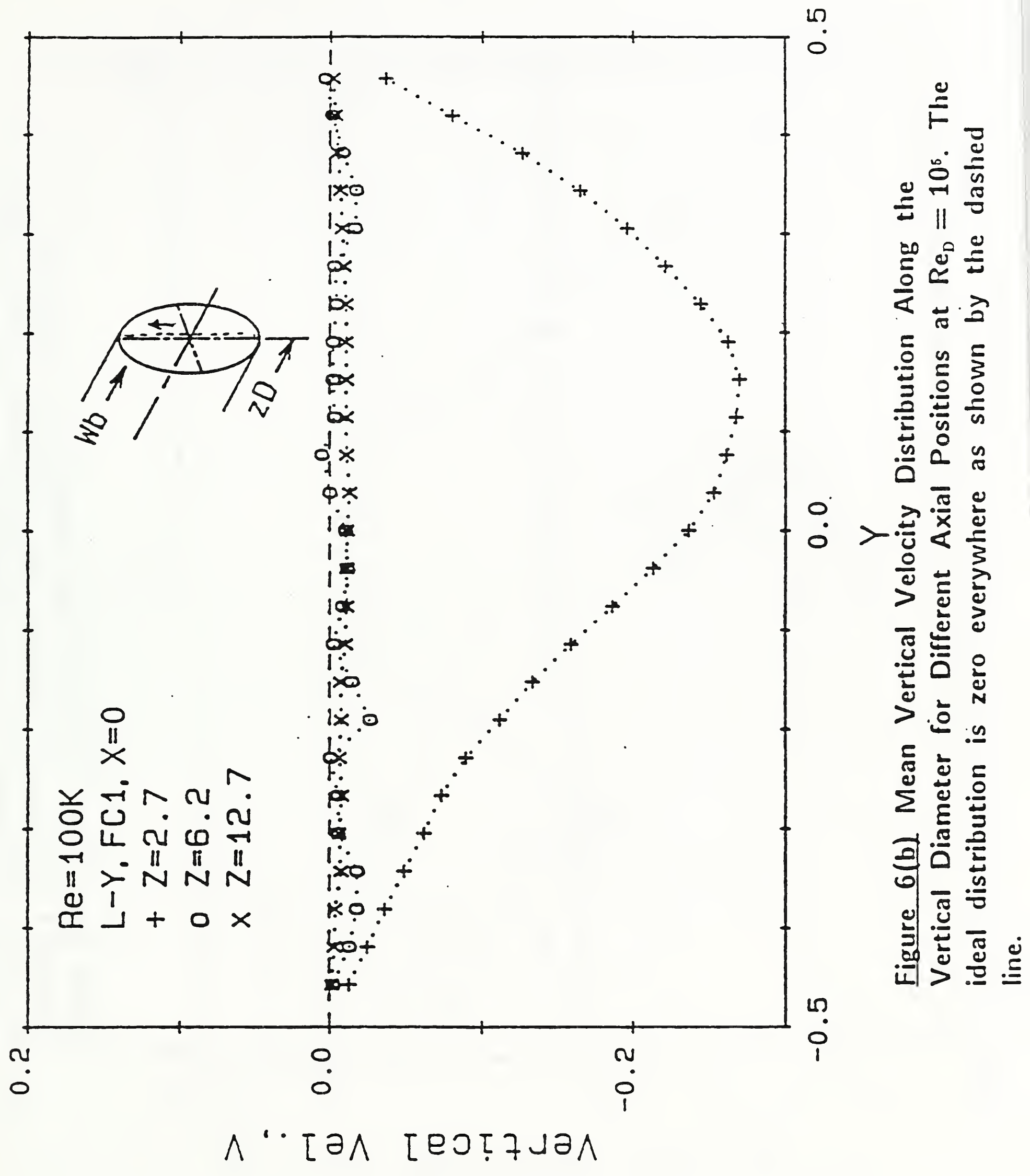




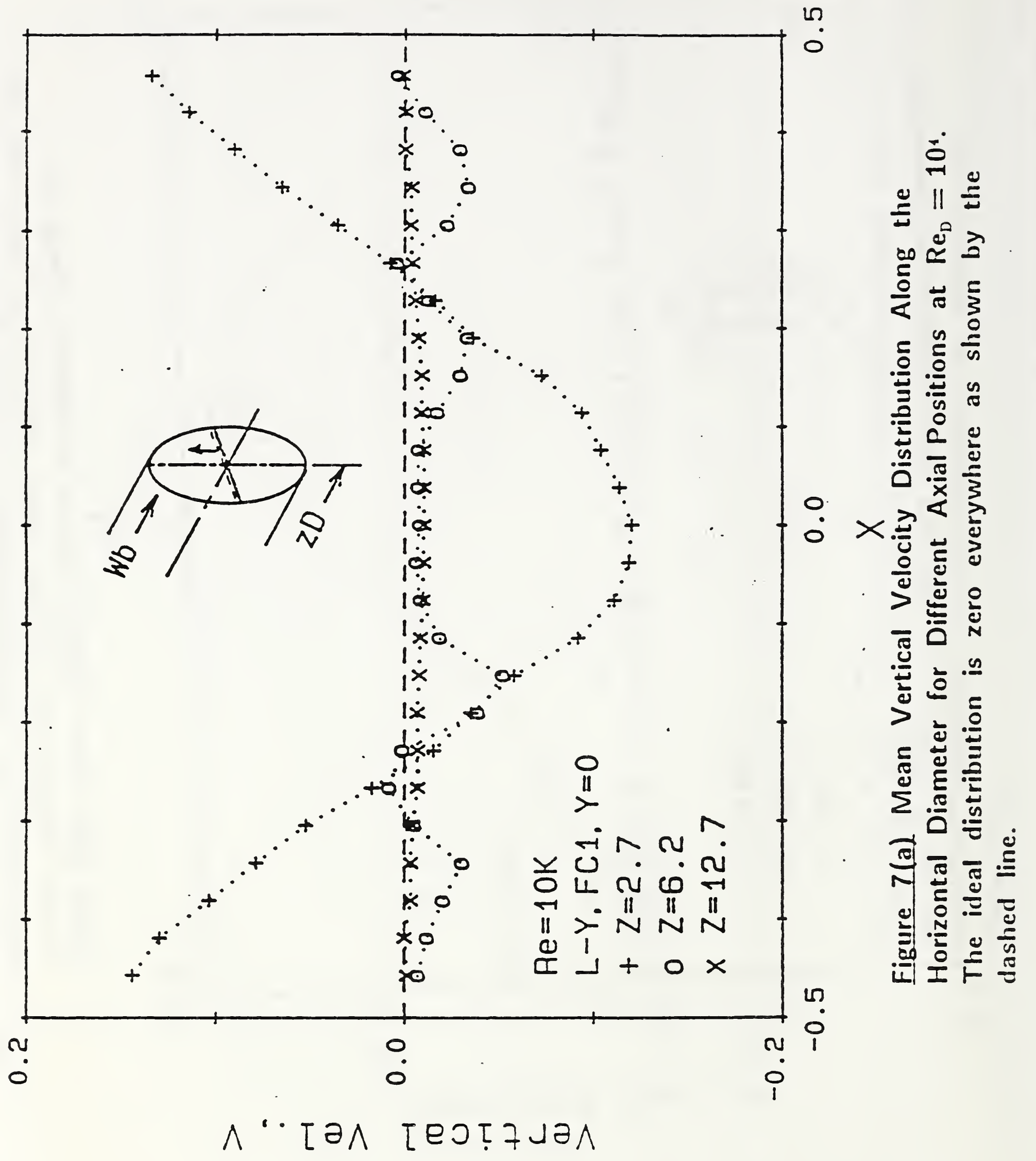




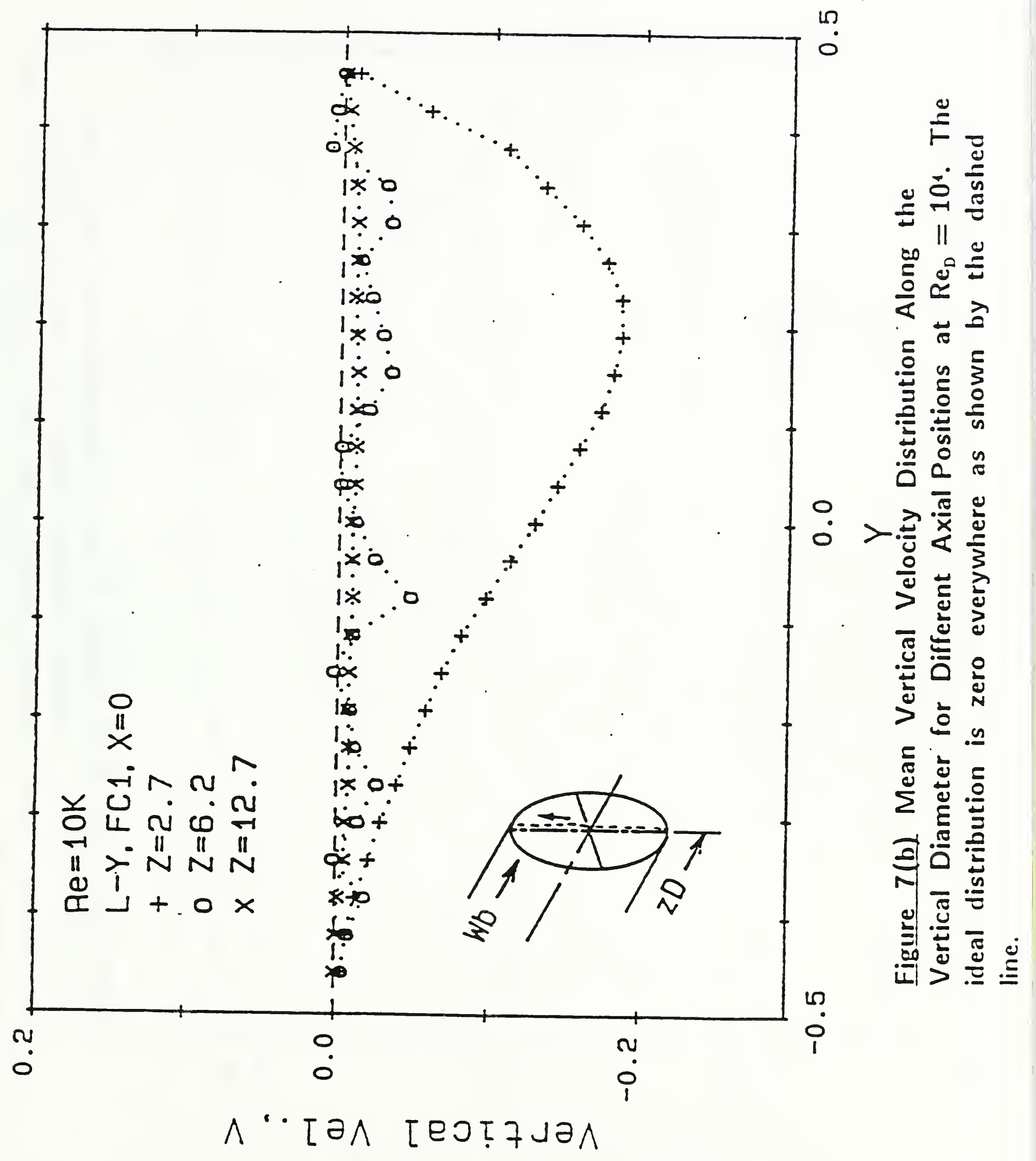




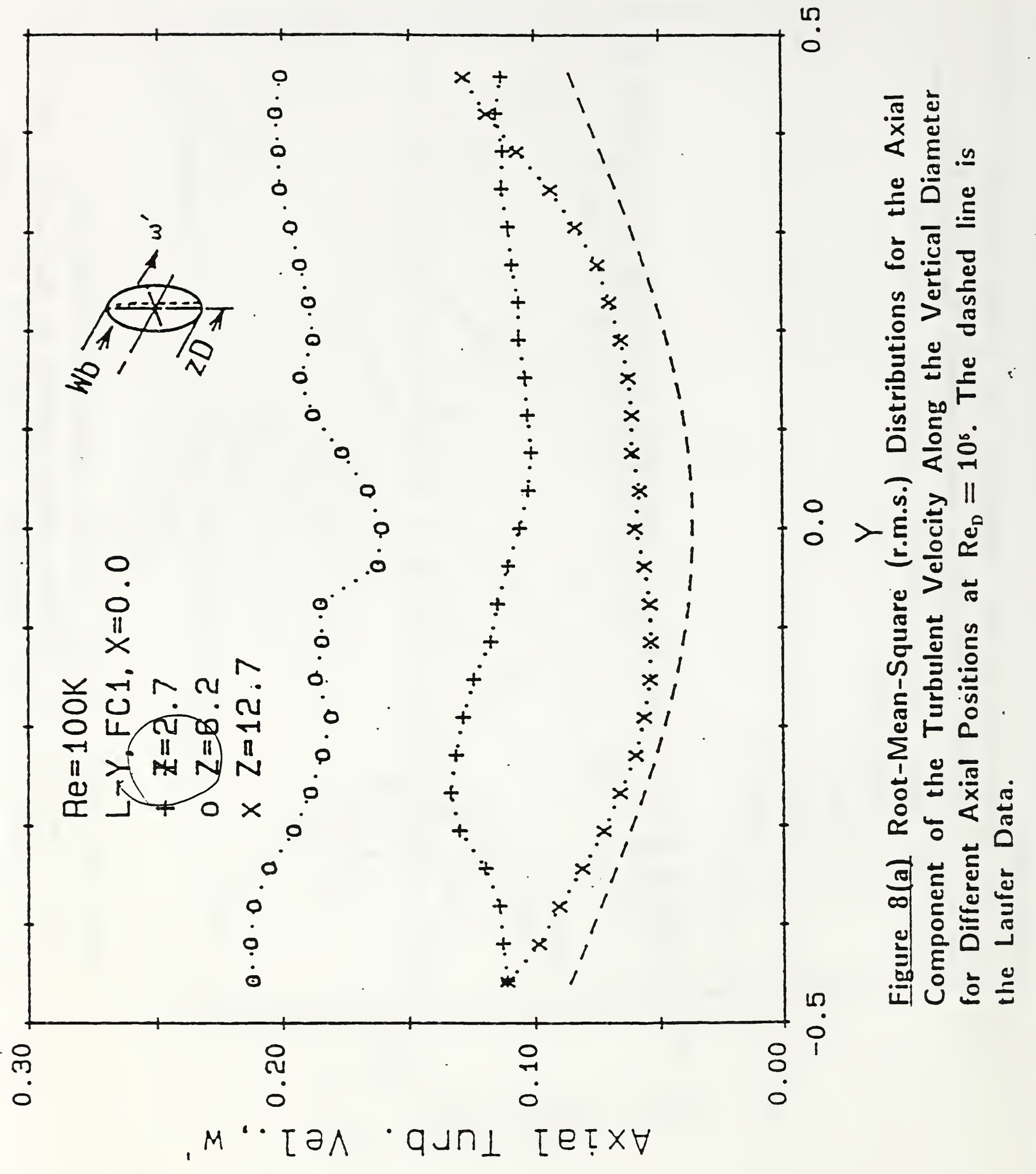




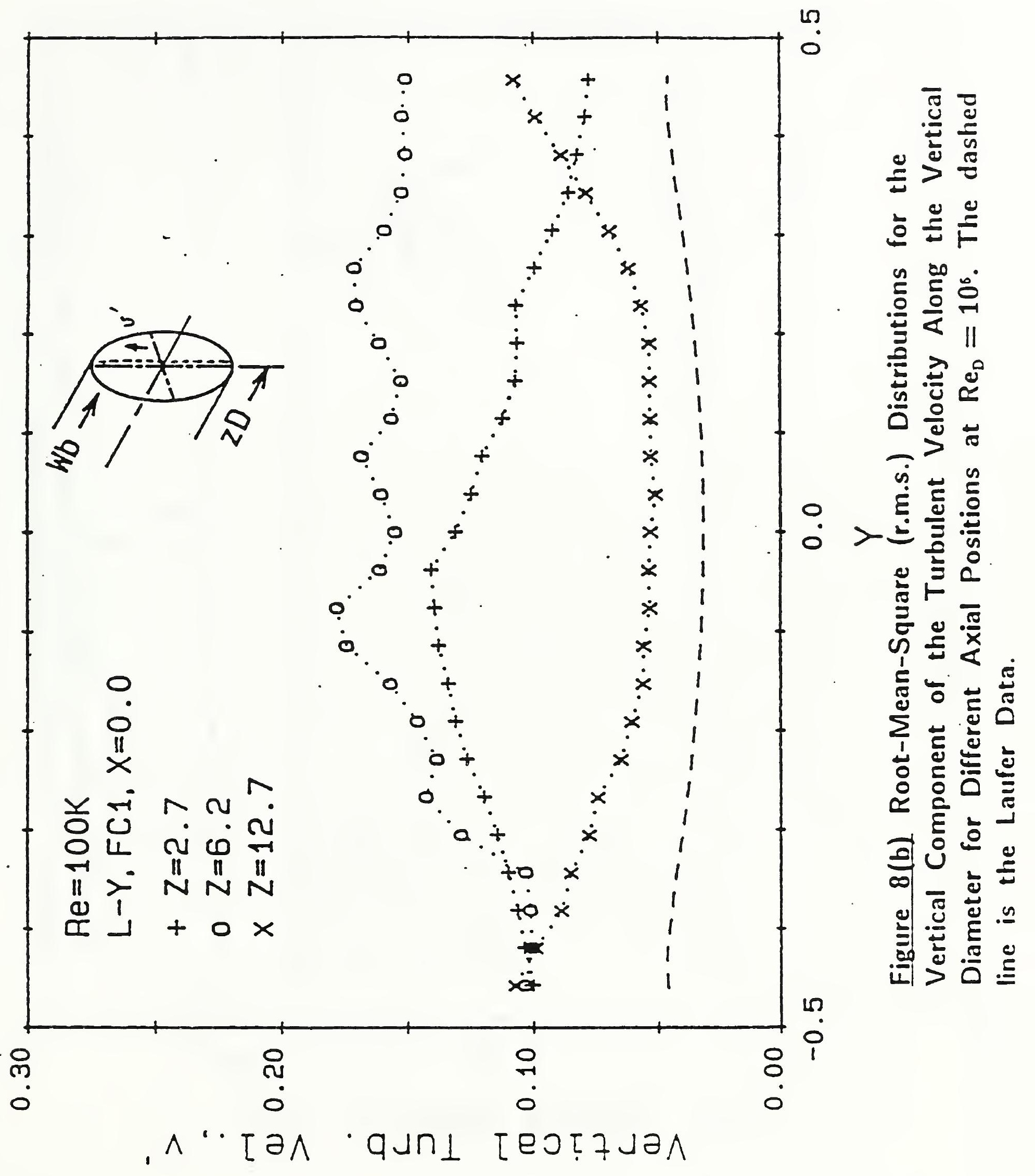




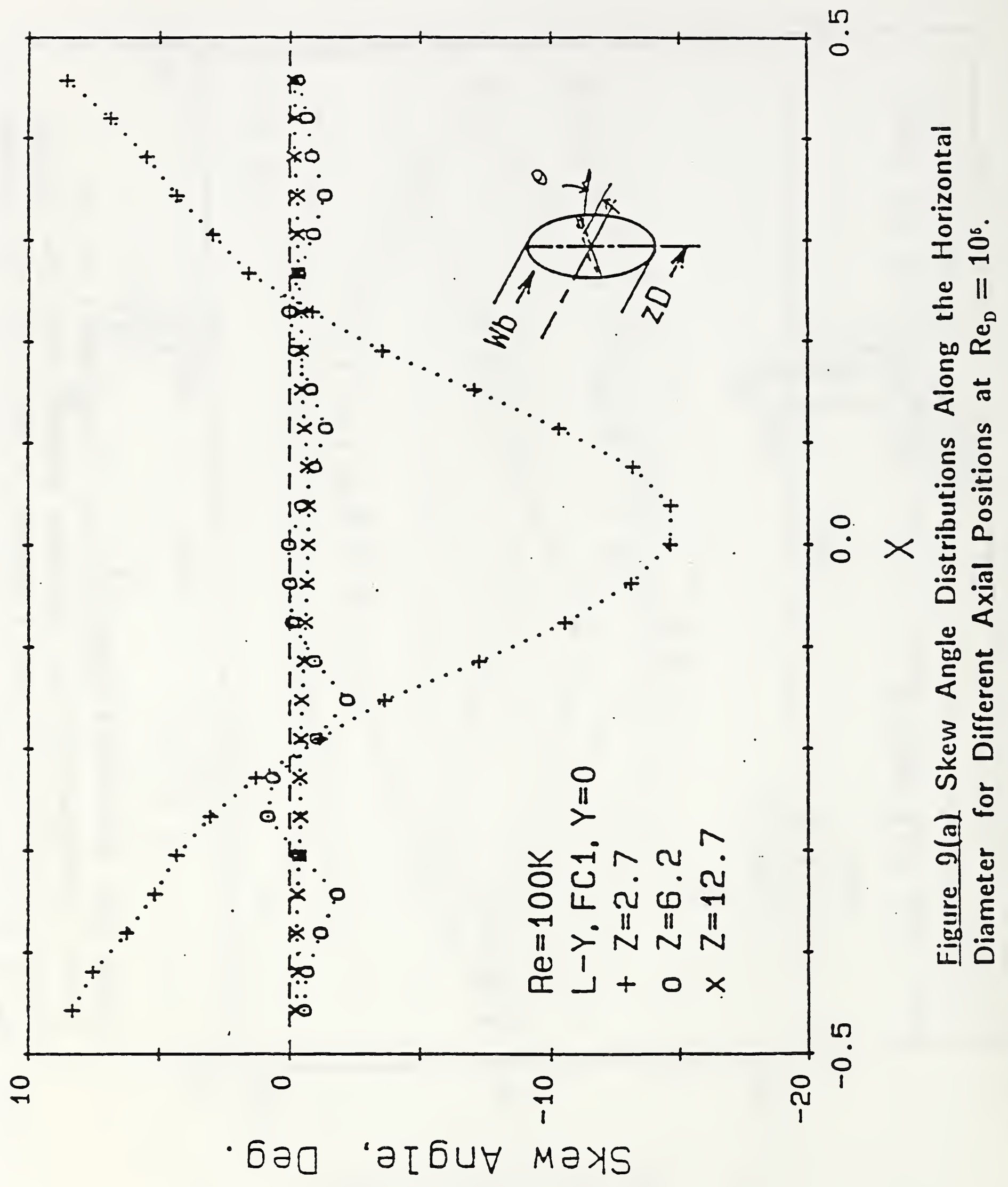




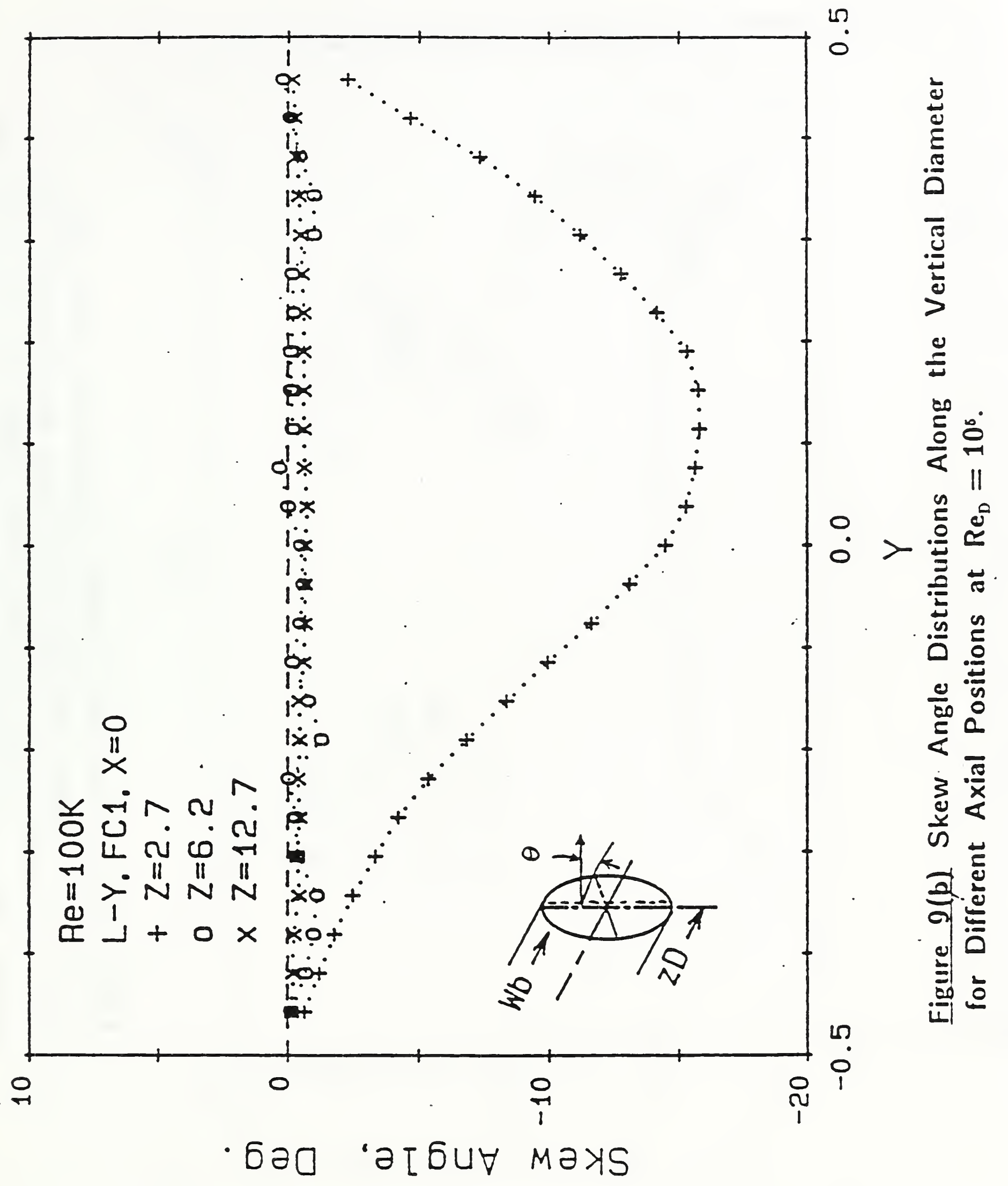




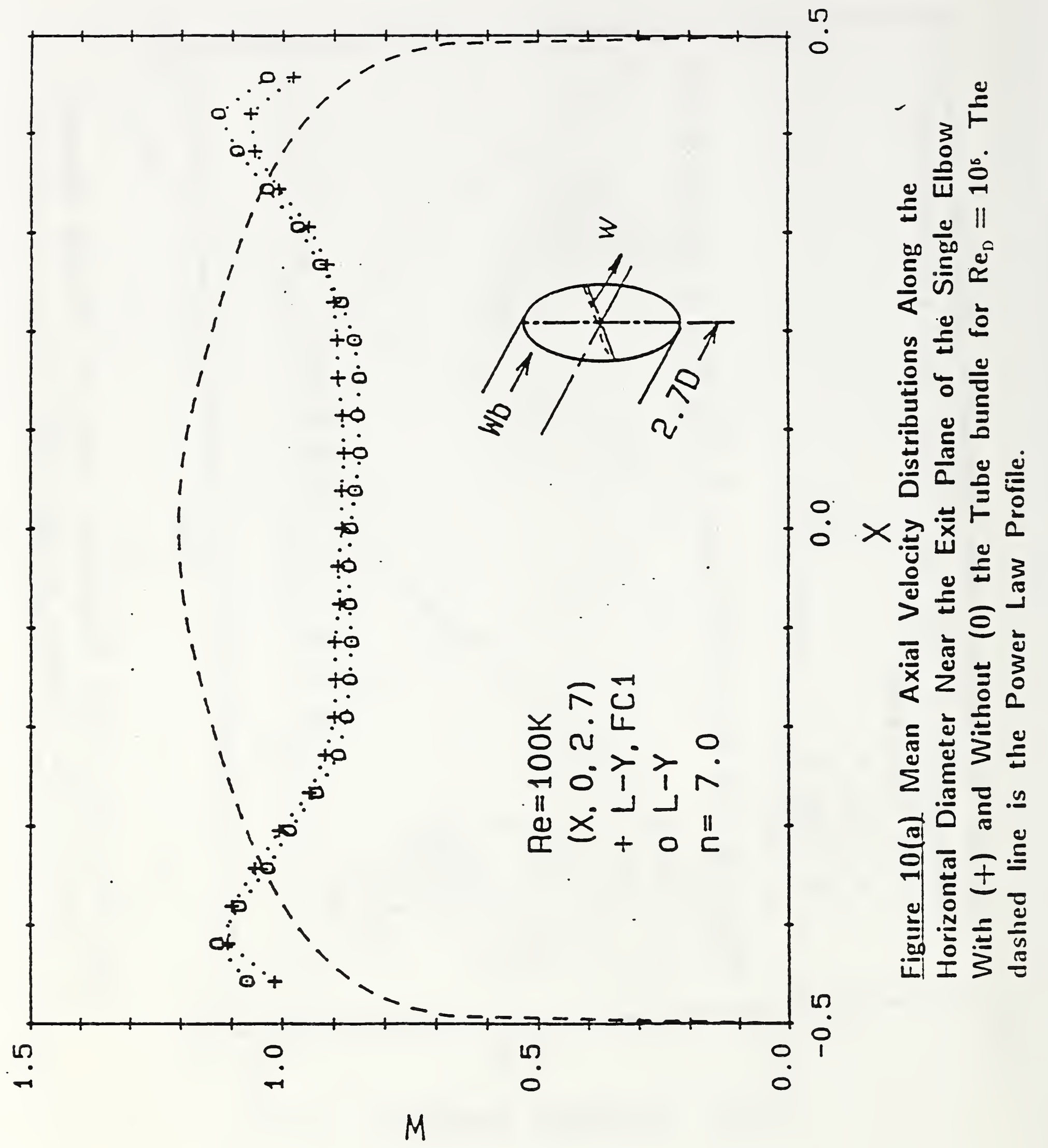




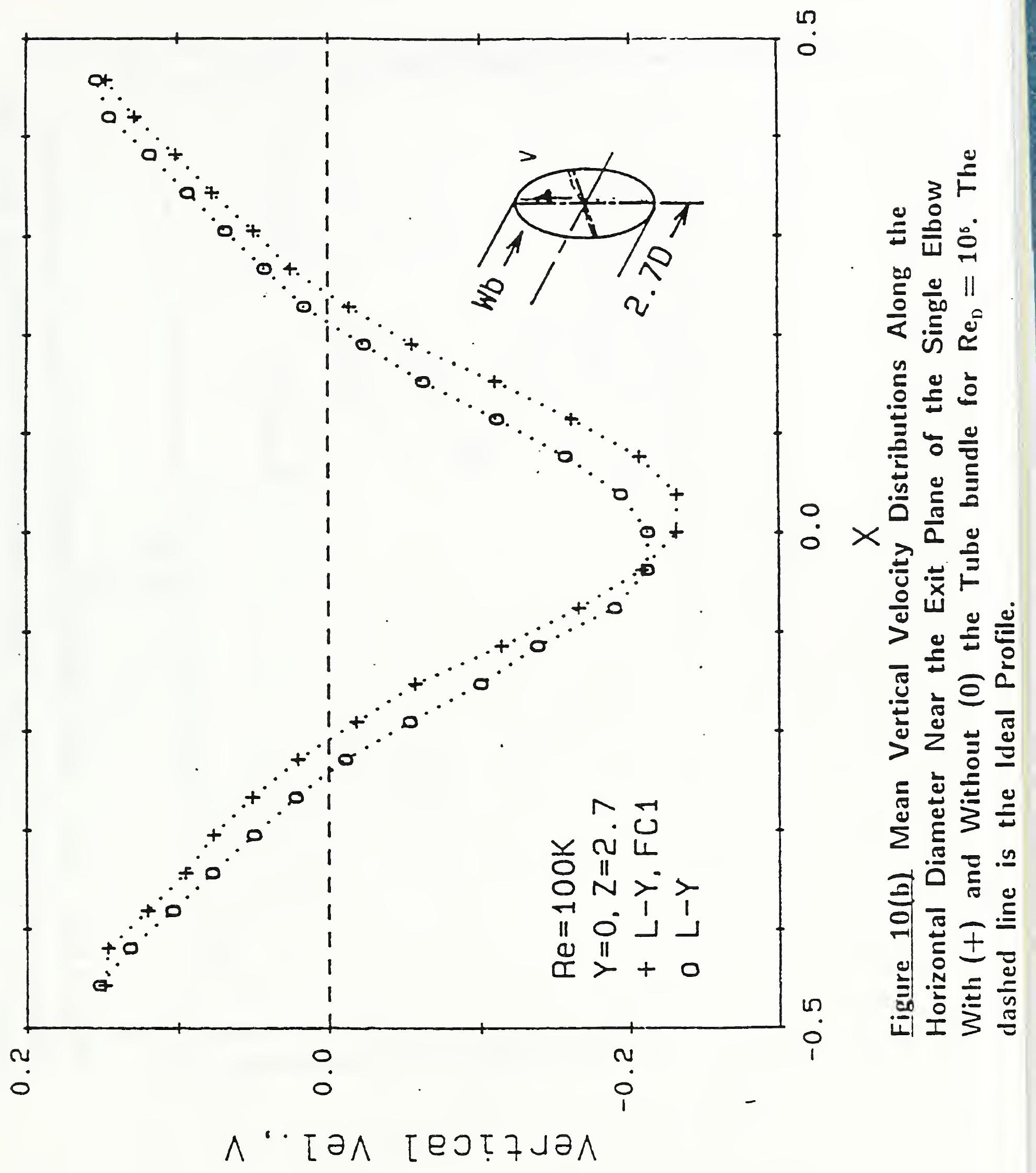




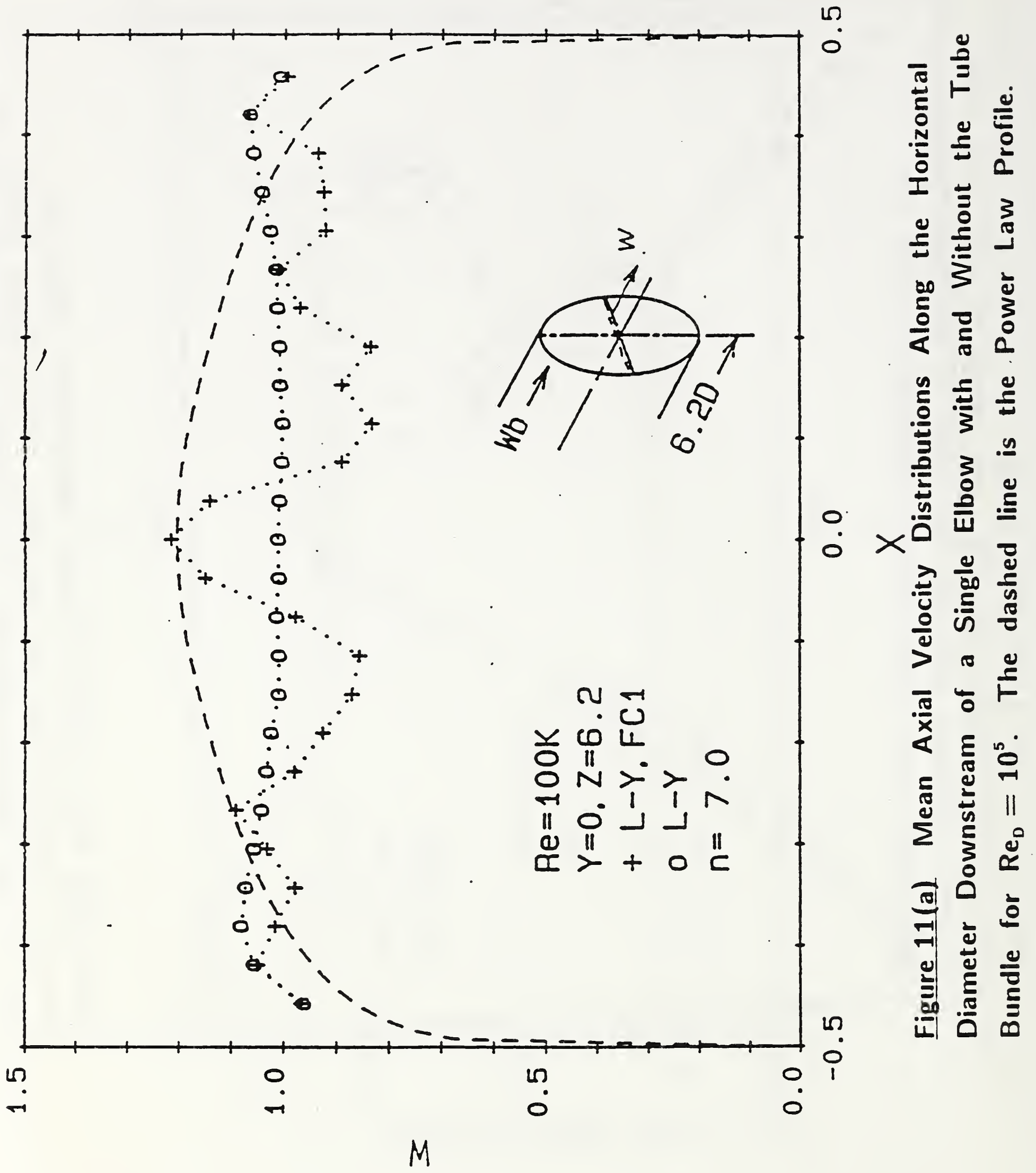




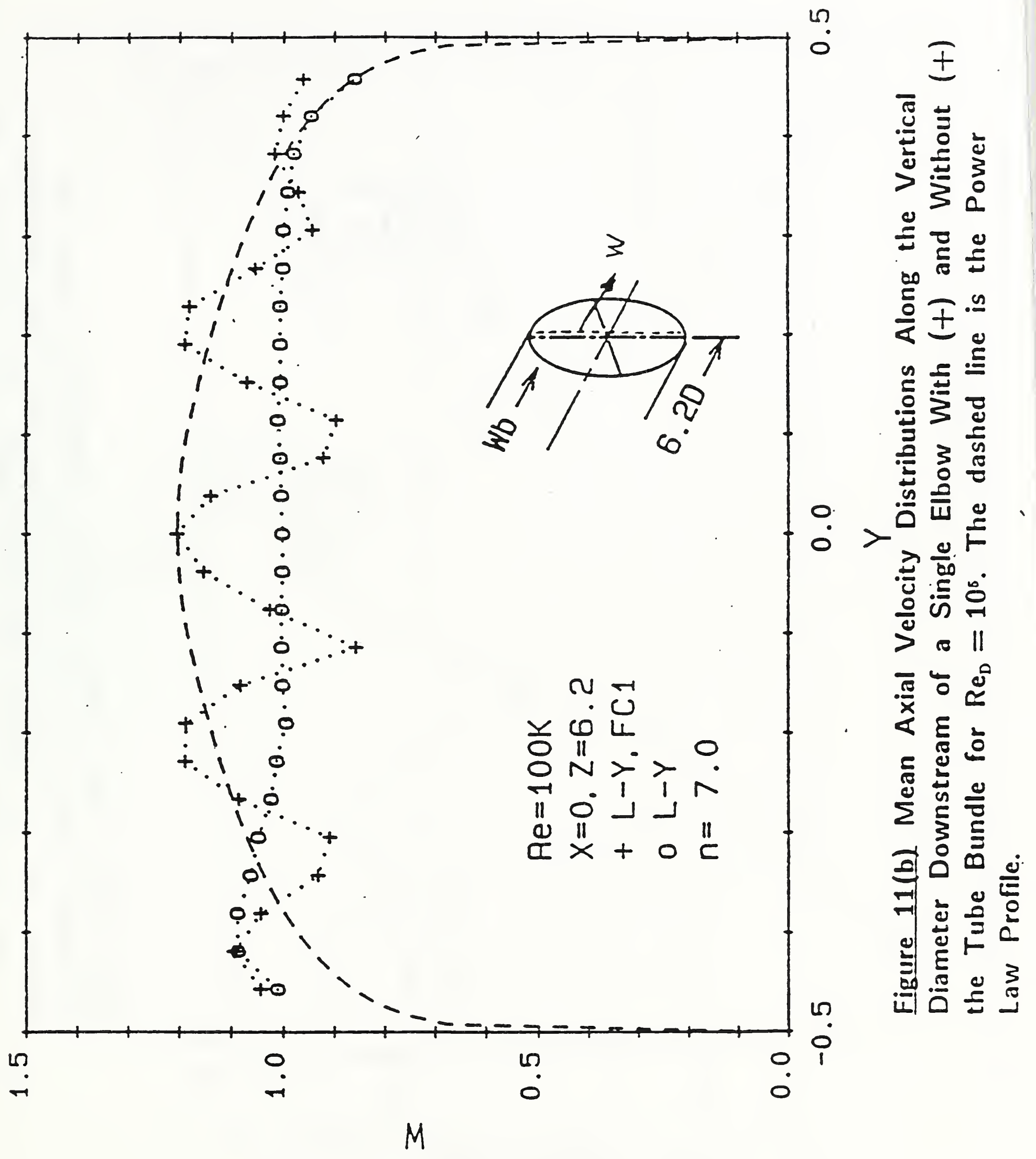




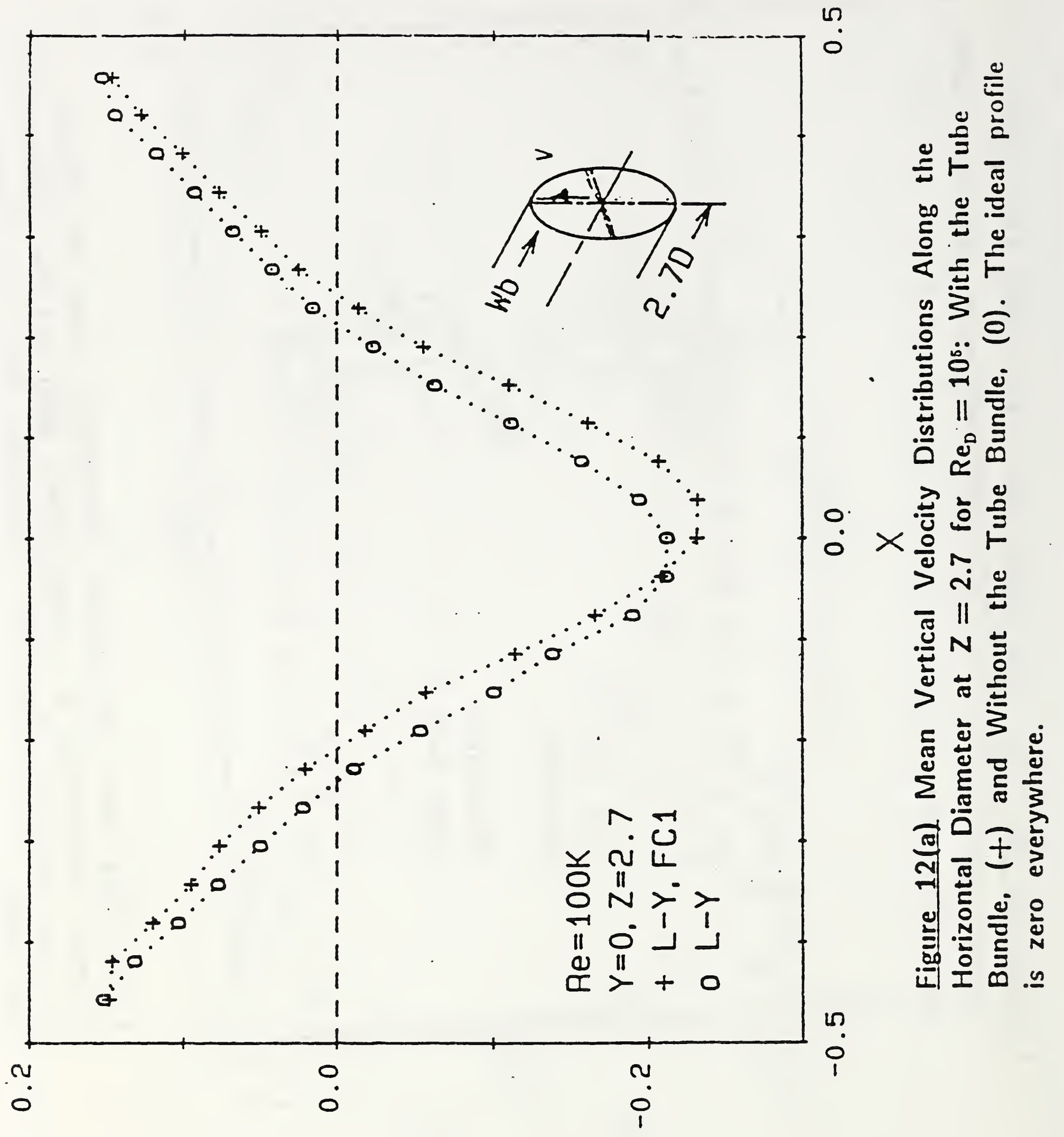

$\Lambda^{\prime}{ }^{\prime}[\partial \wedge$ [eot] 


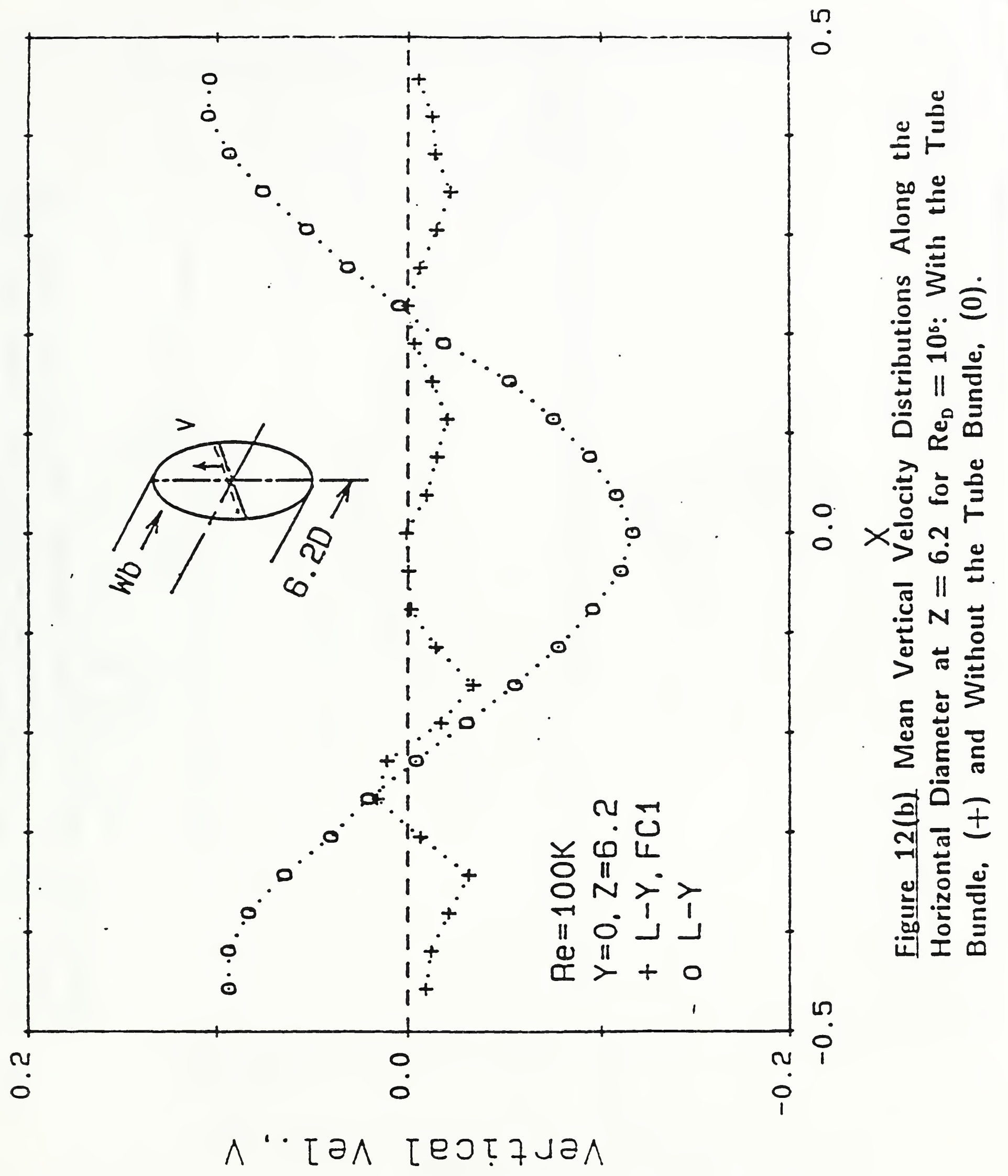




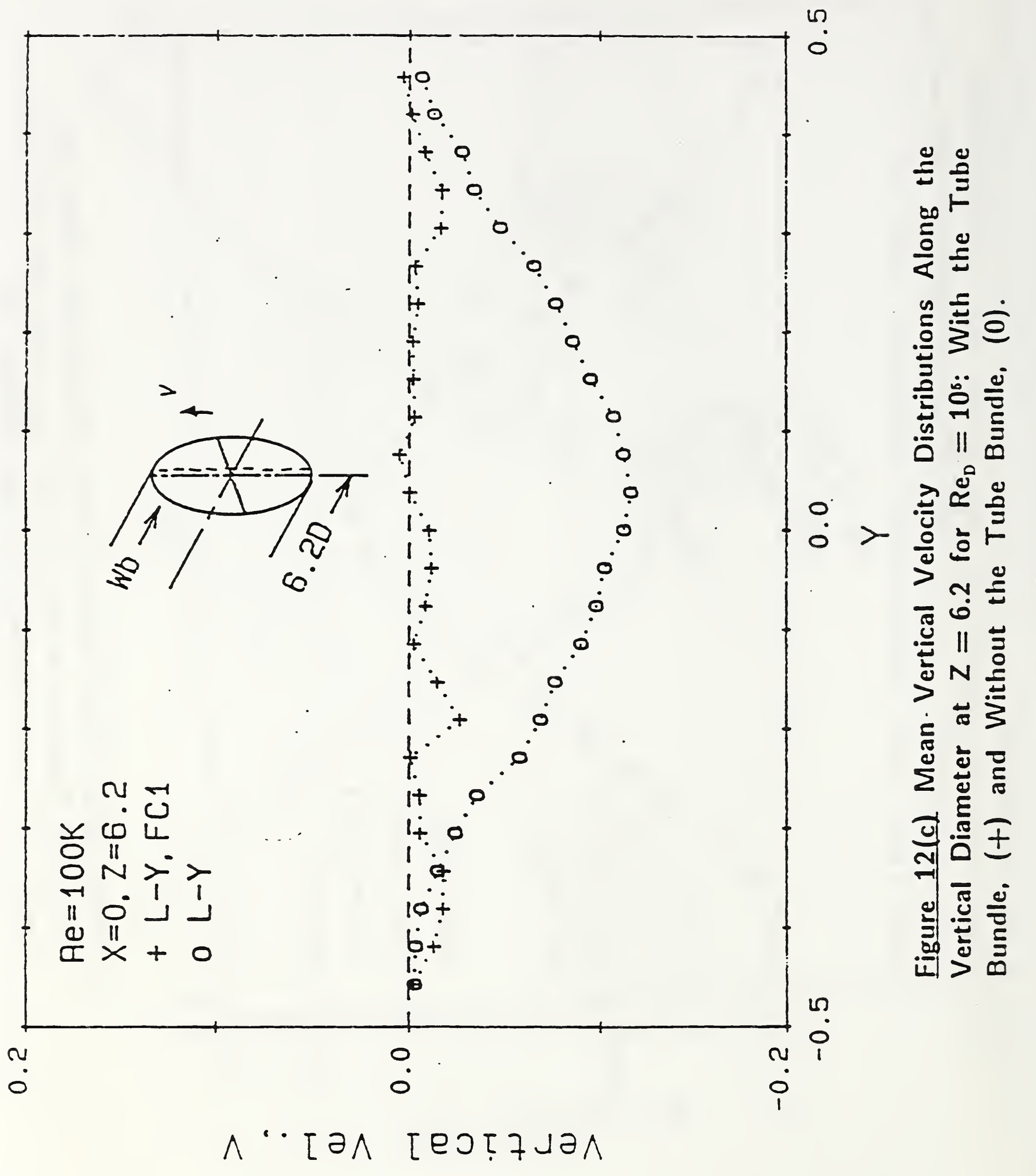




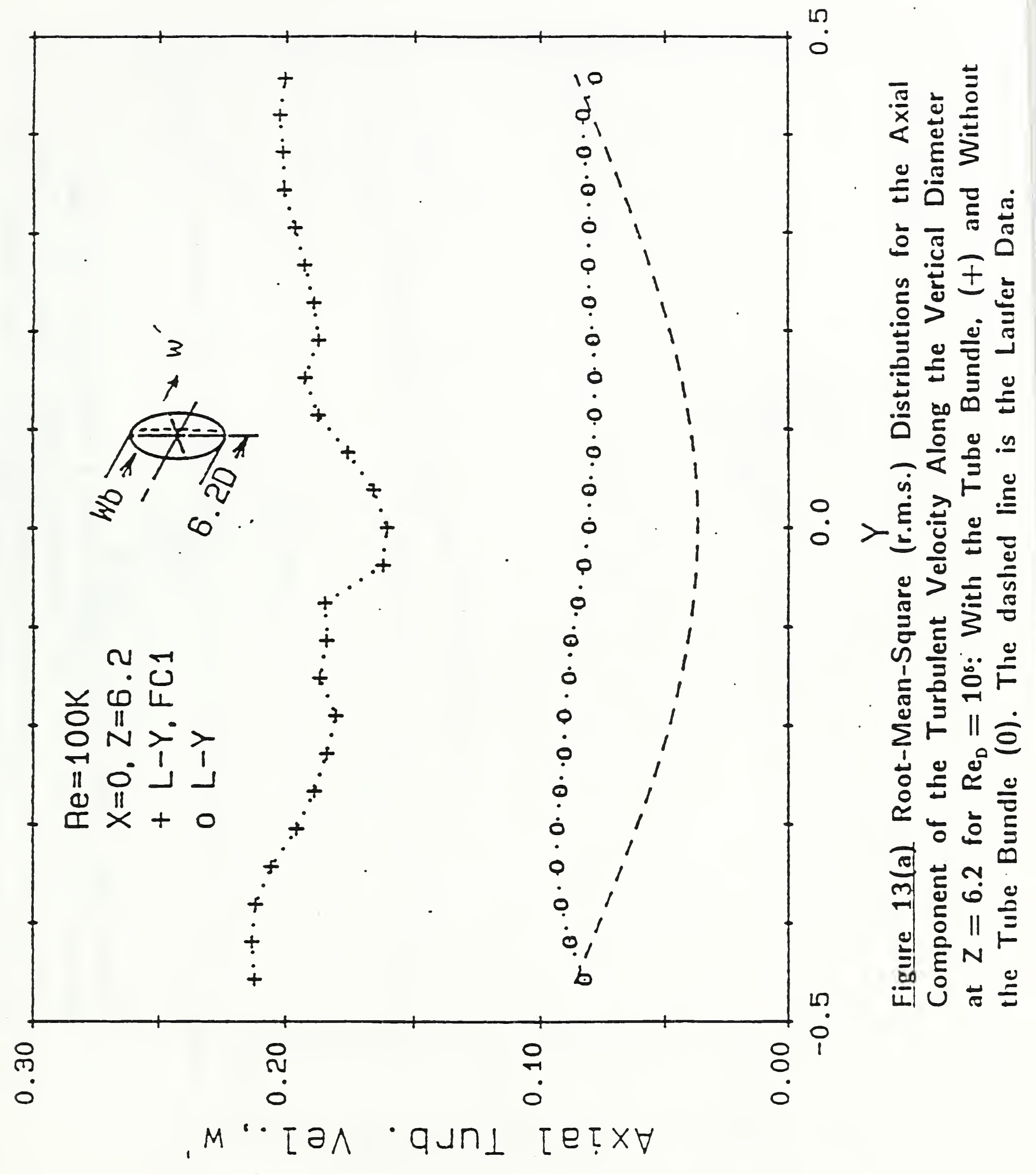




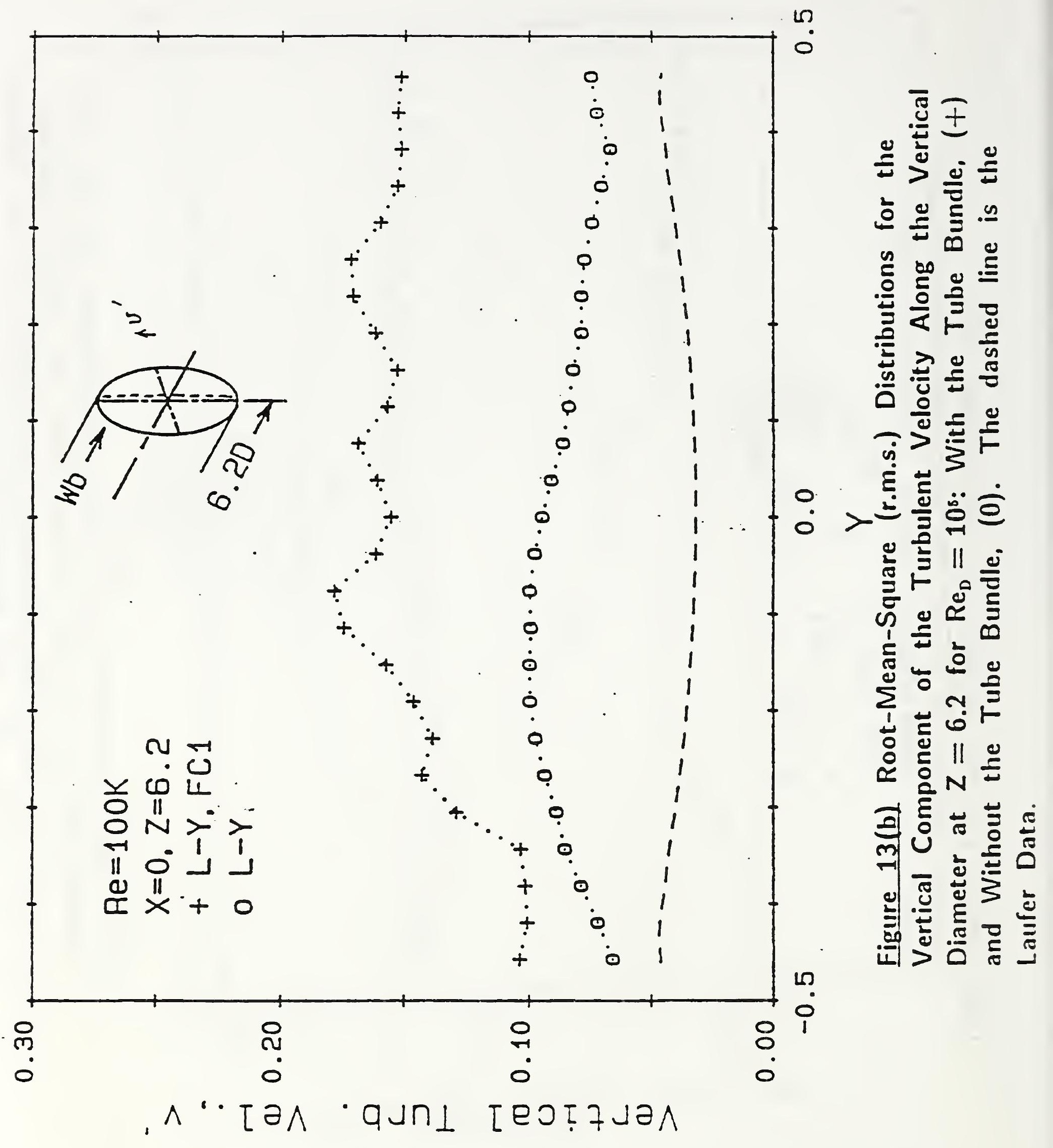




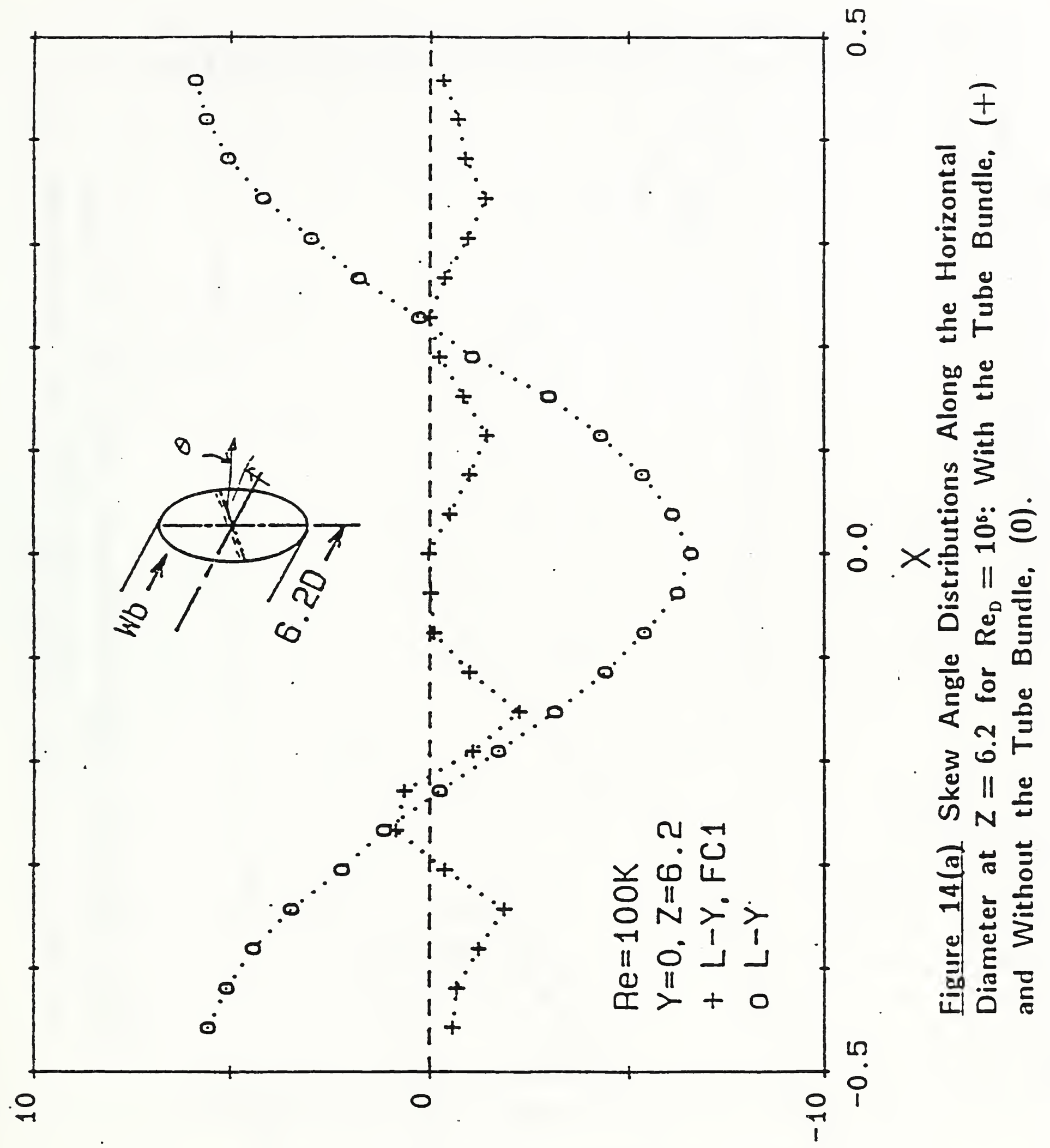

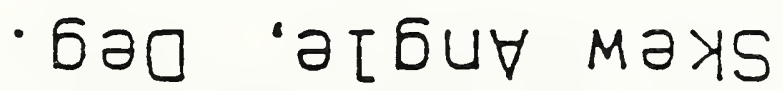




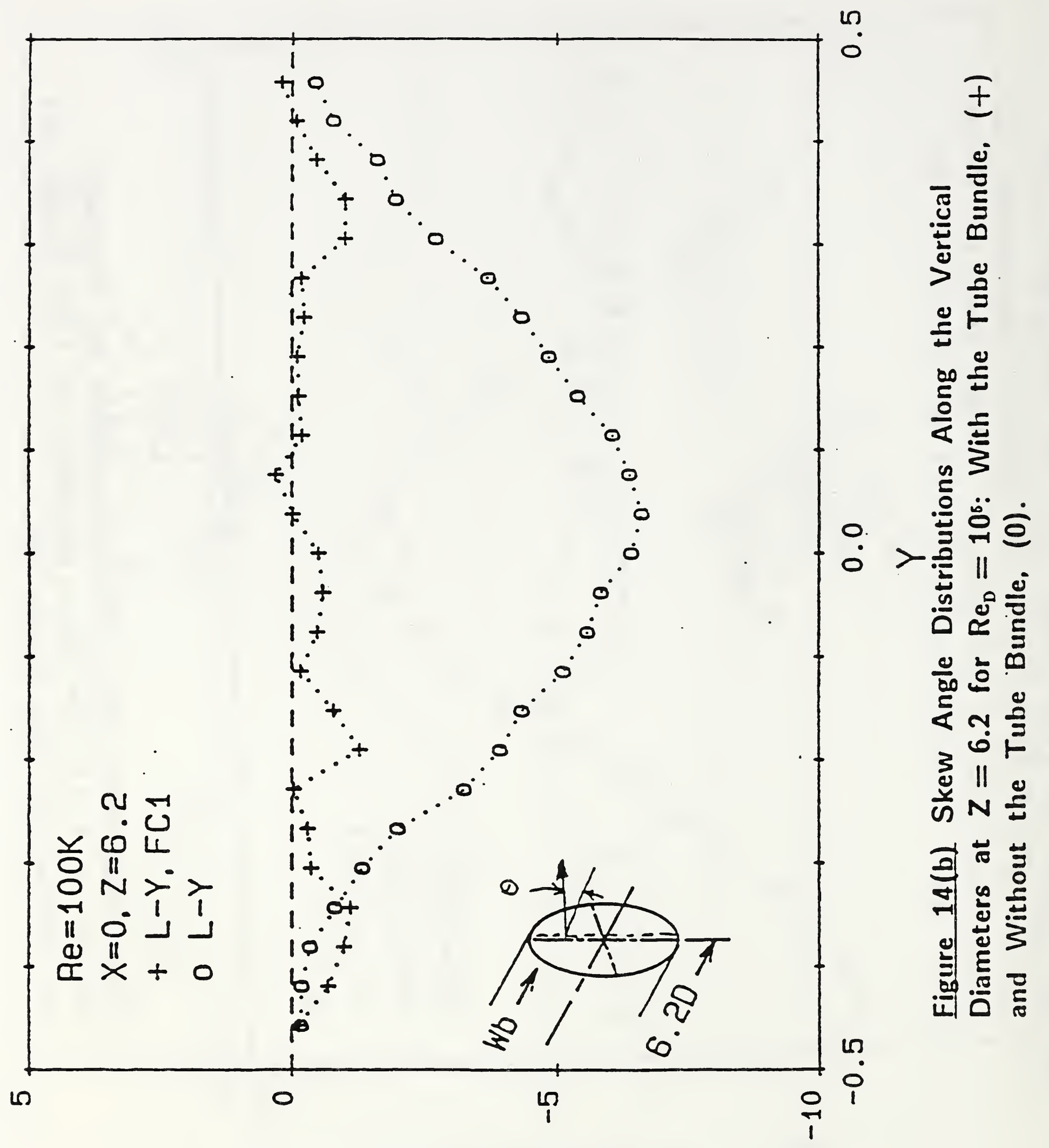

- баם 'a[бu甘 Maxs 


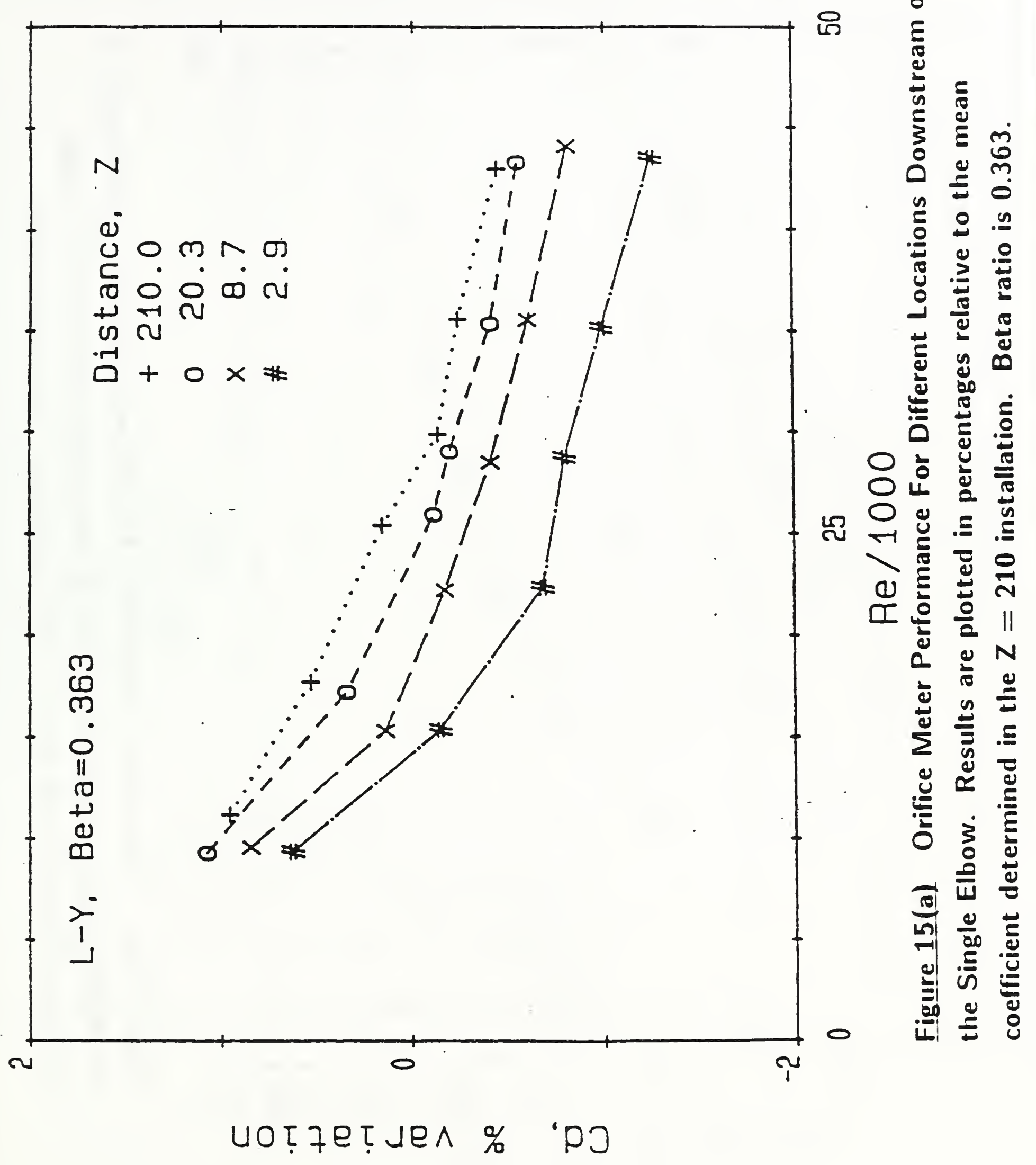




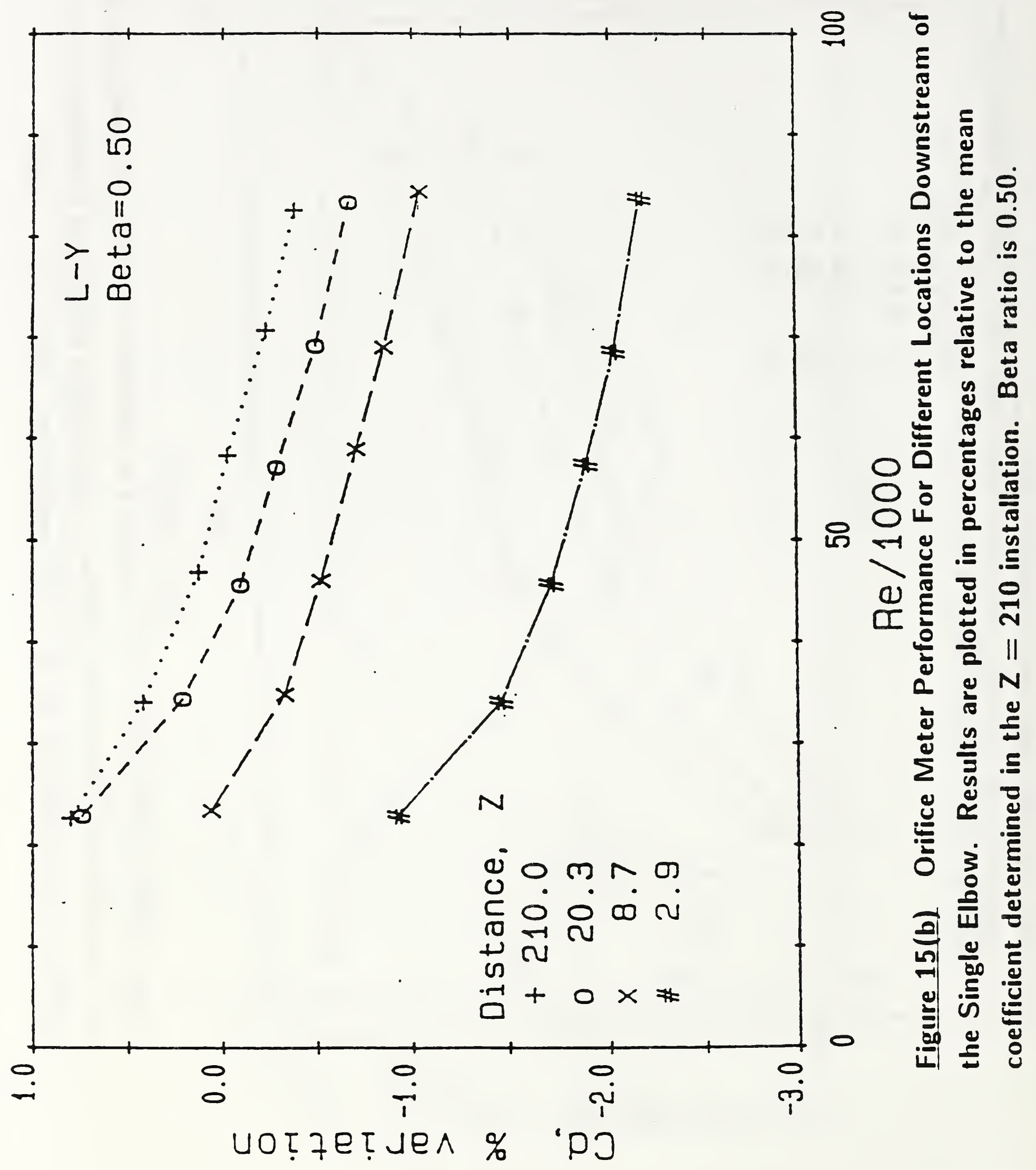




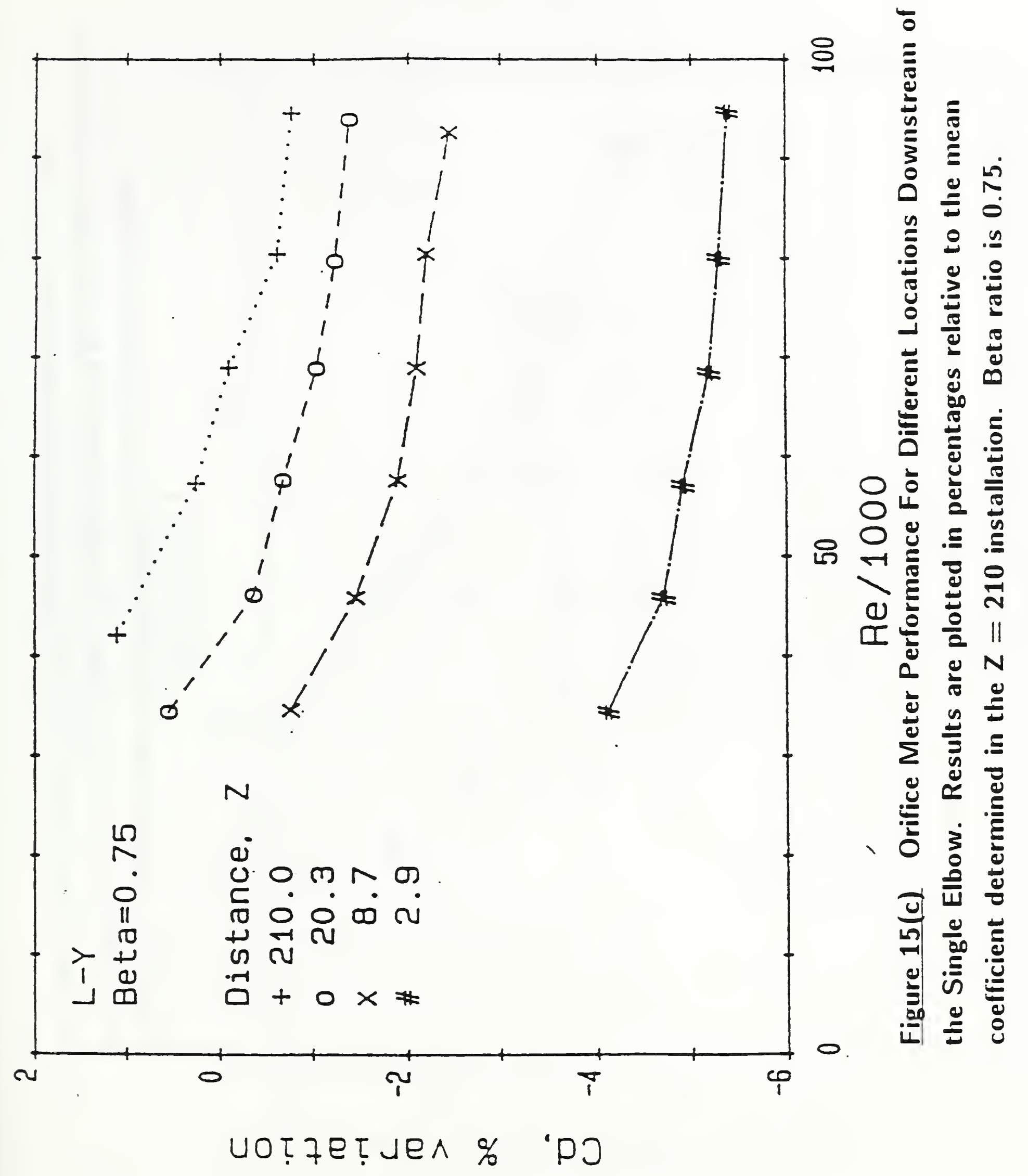




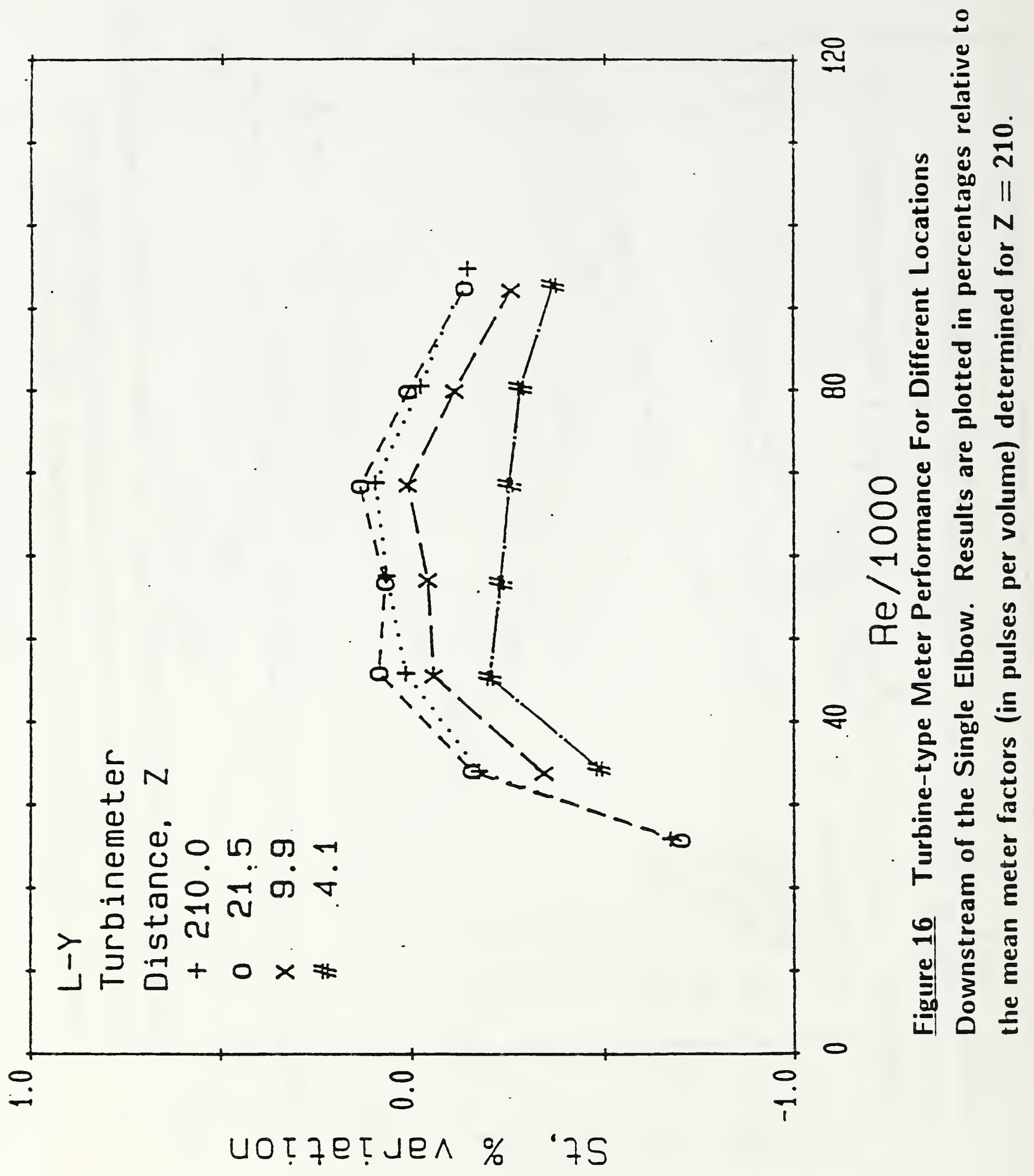




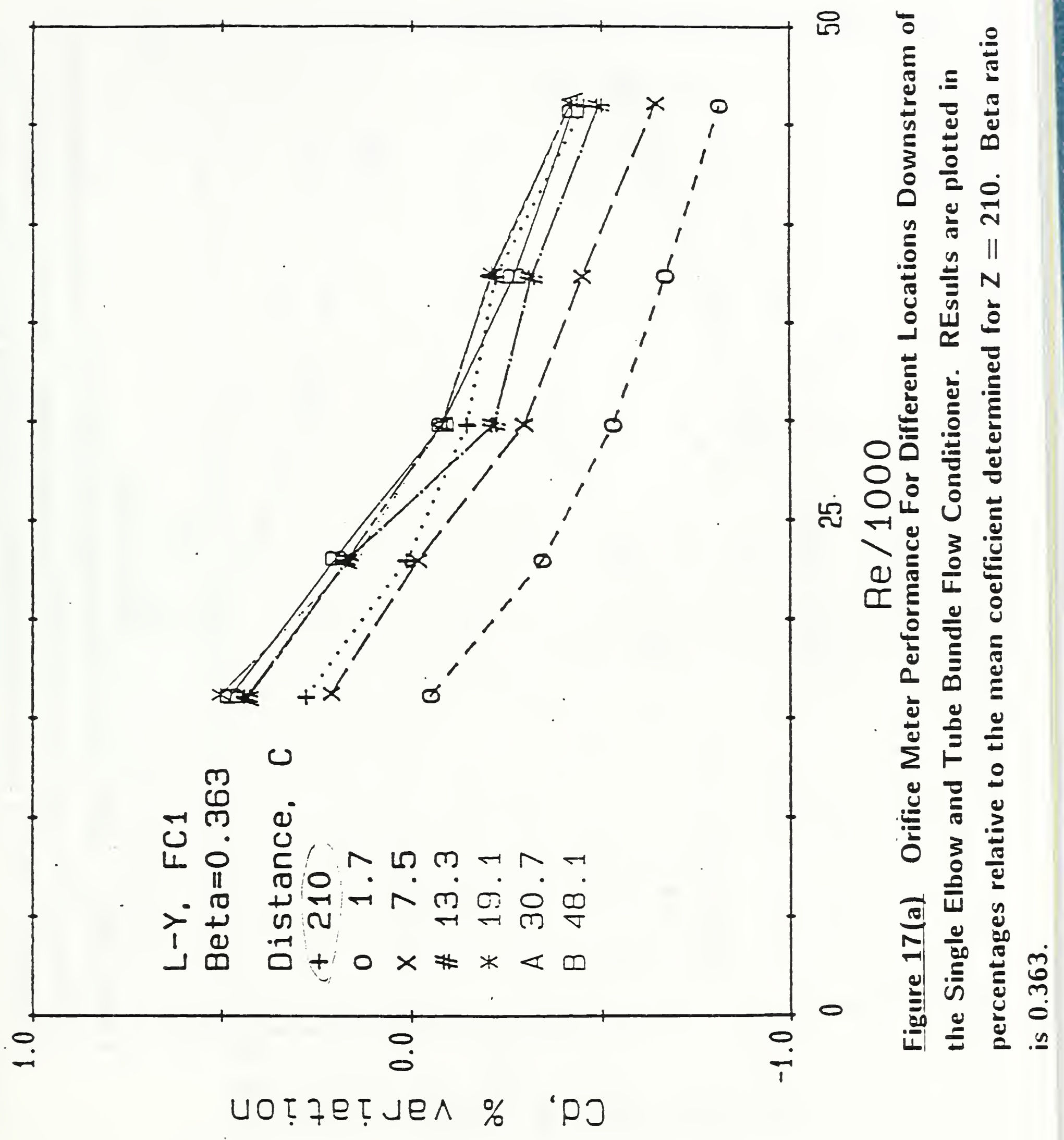




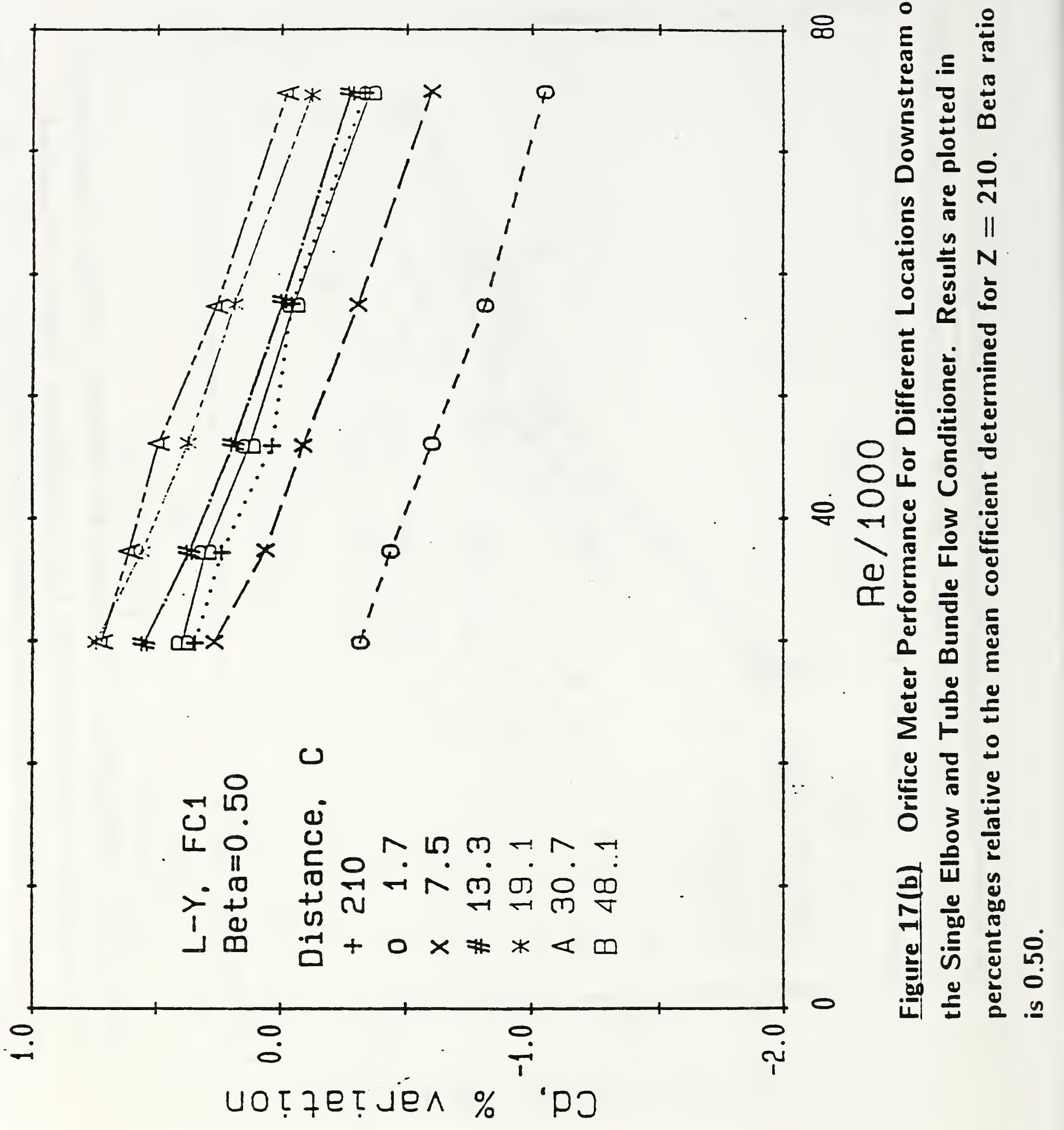




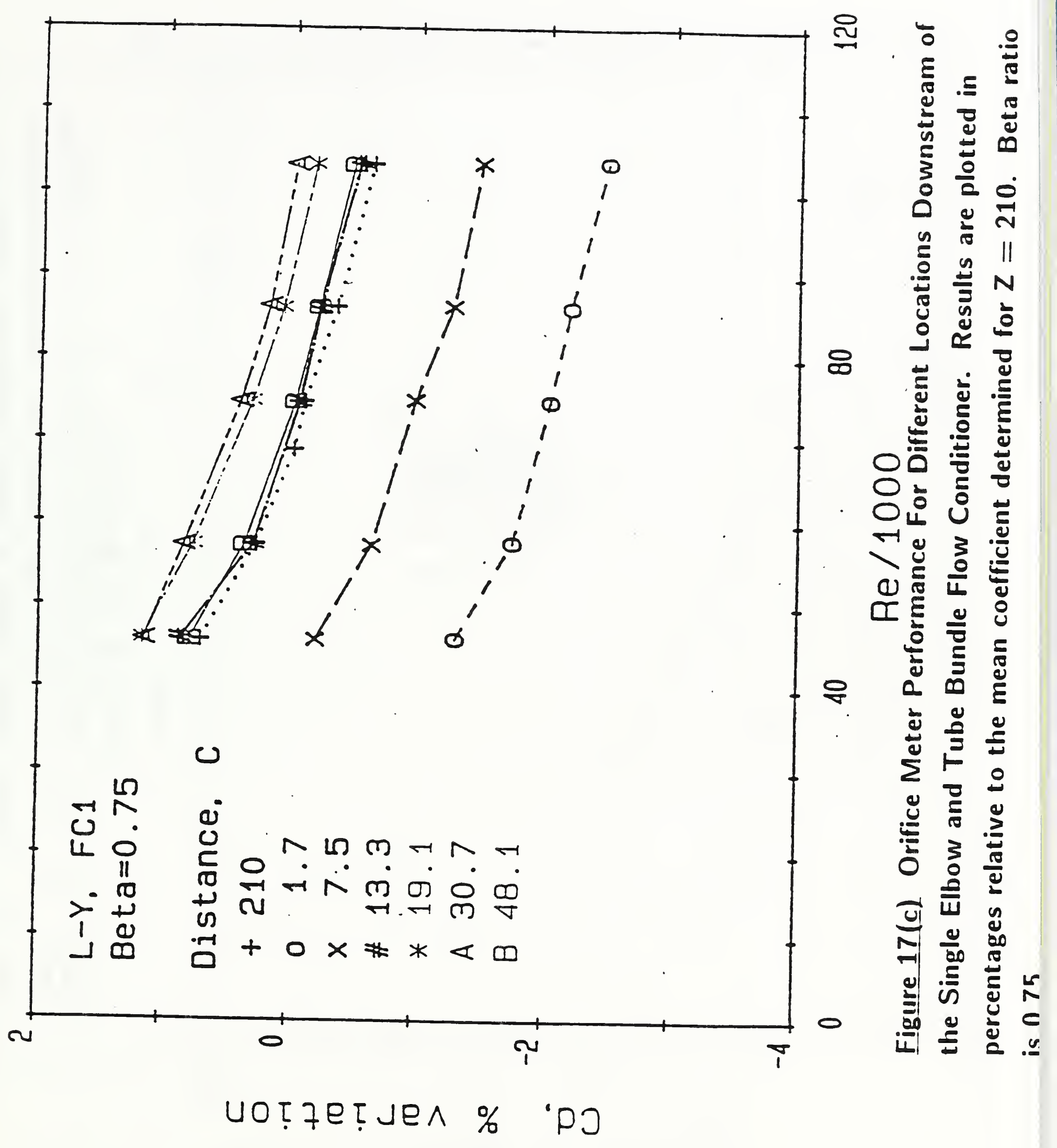




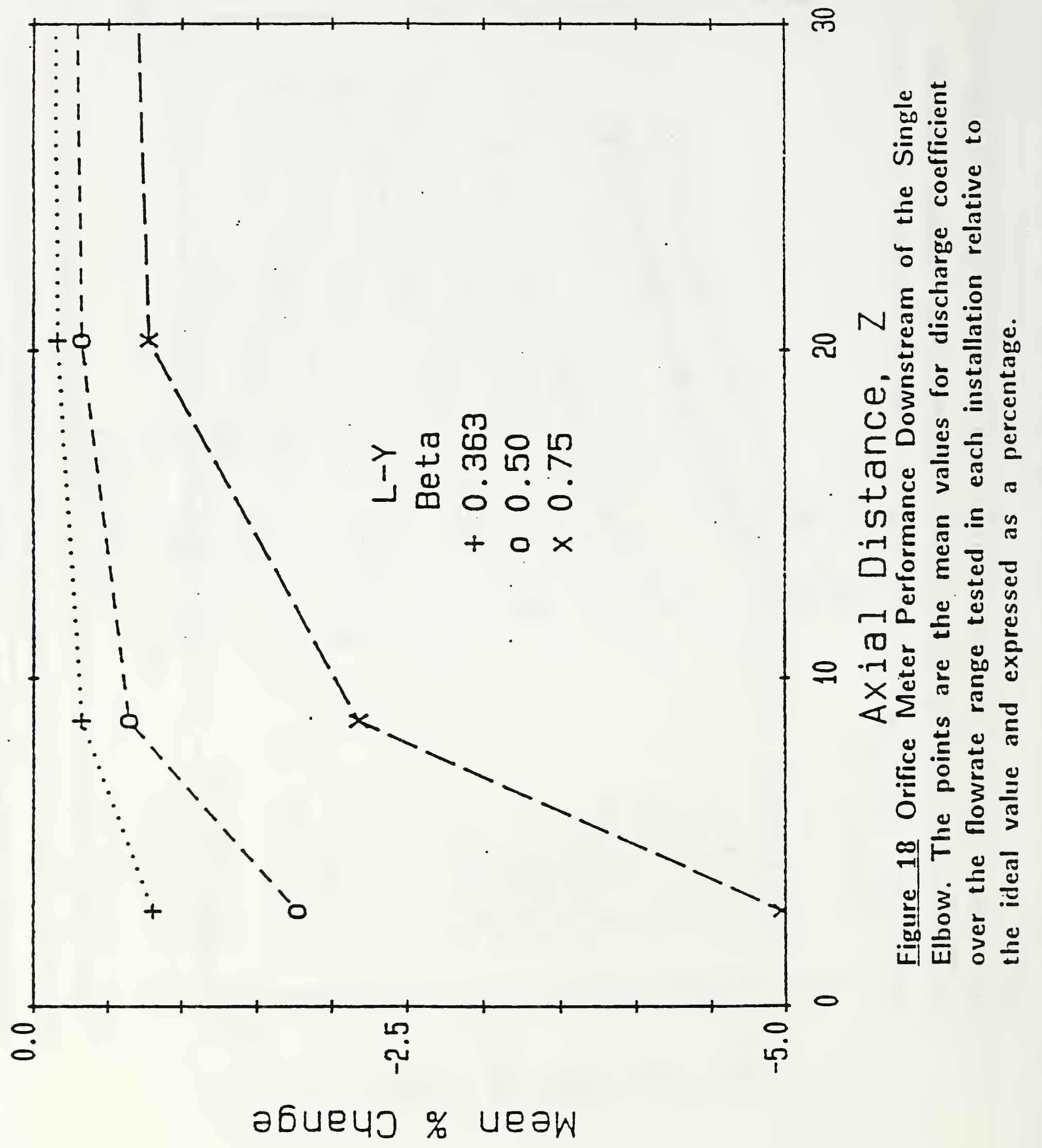




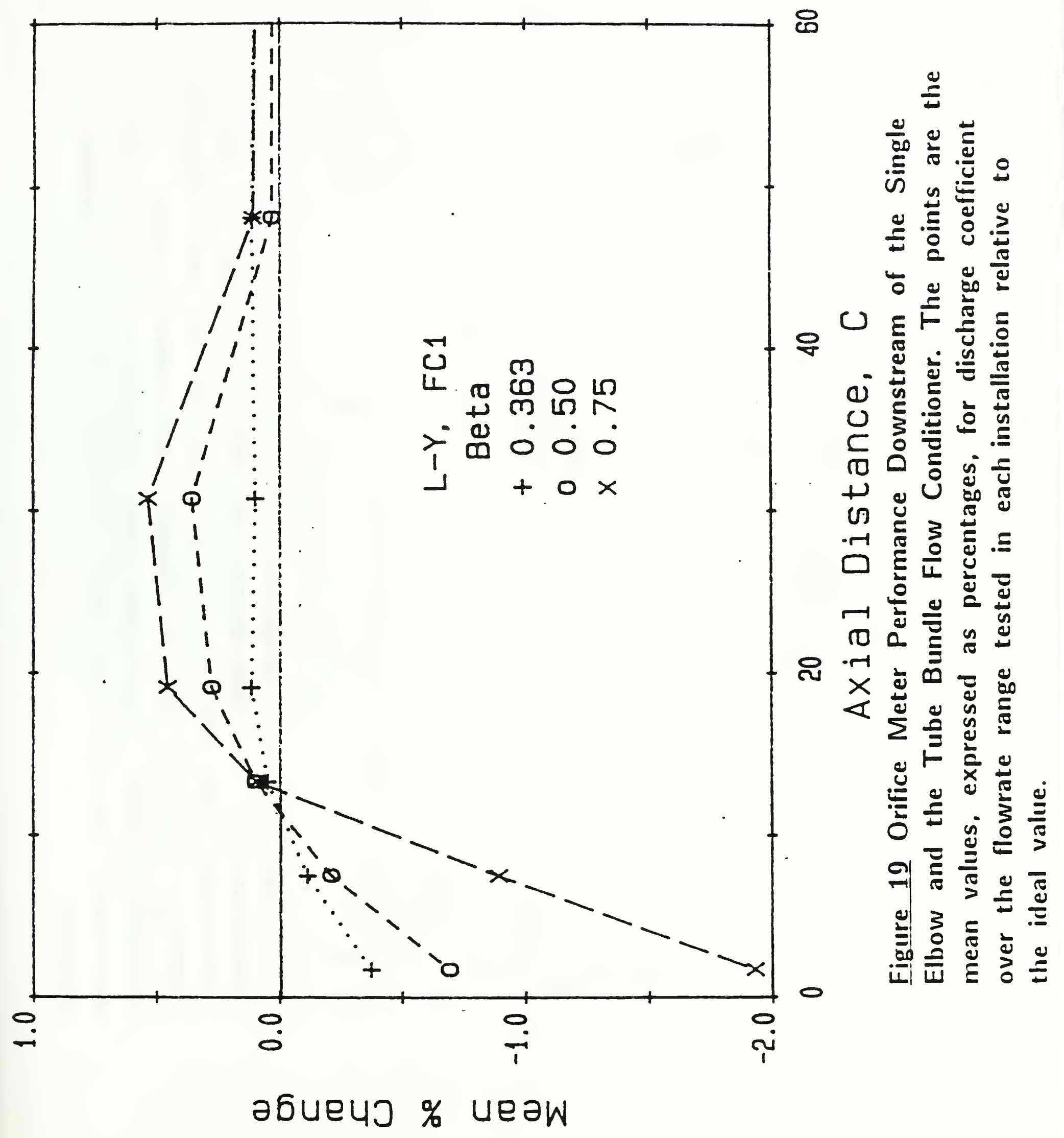




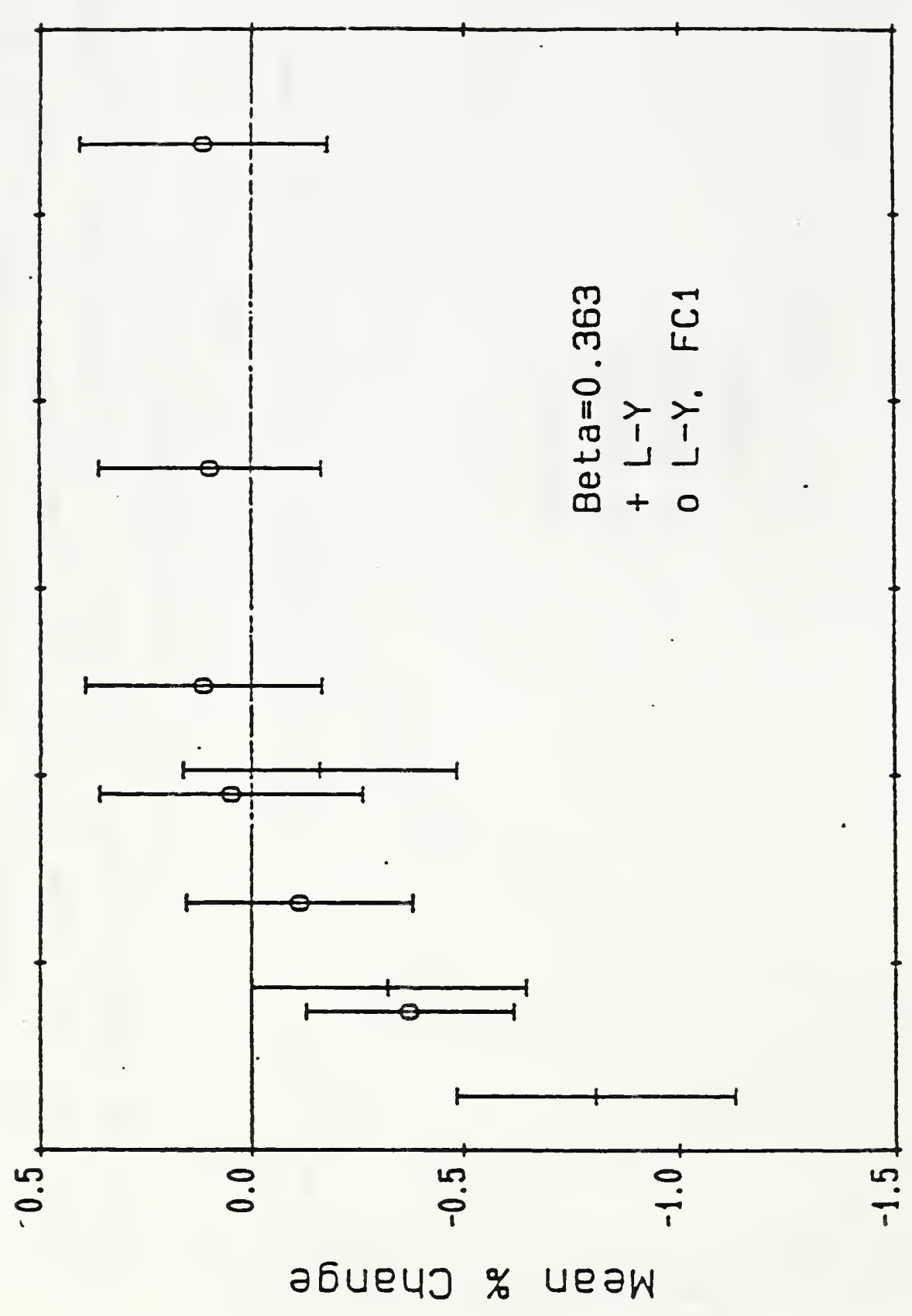

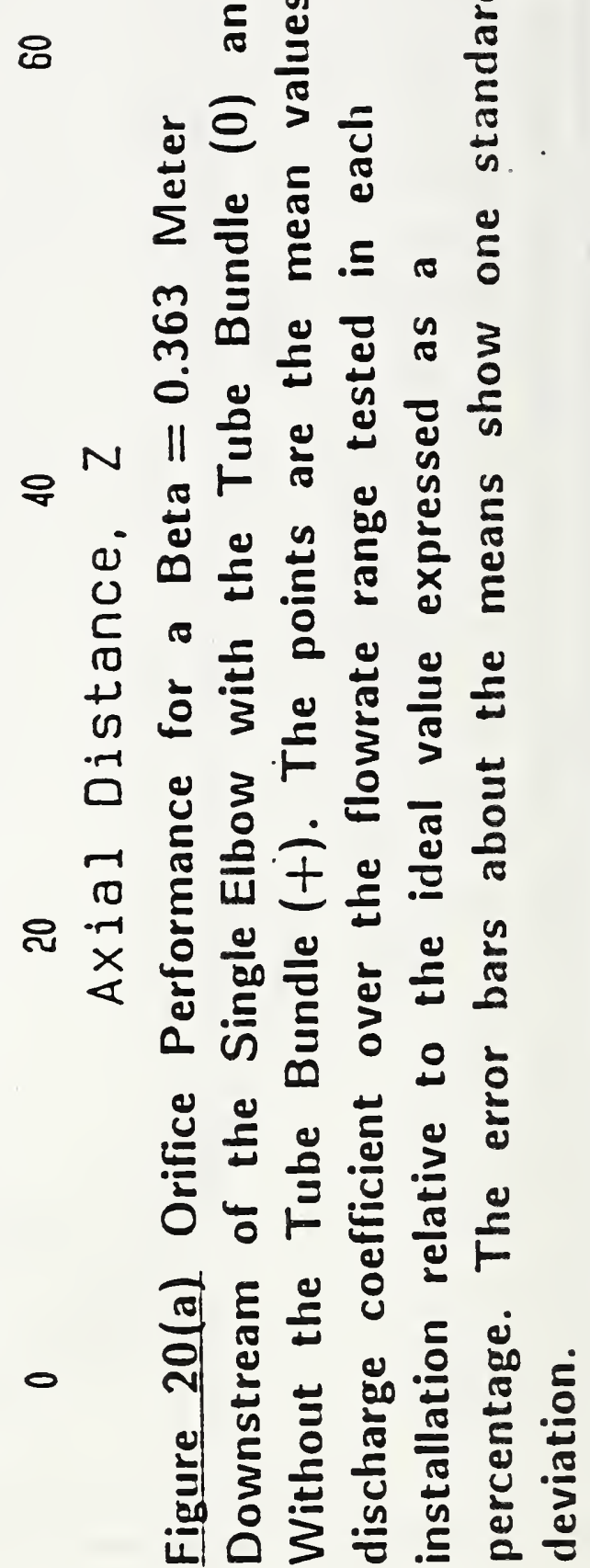




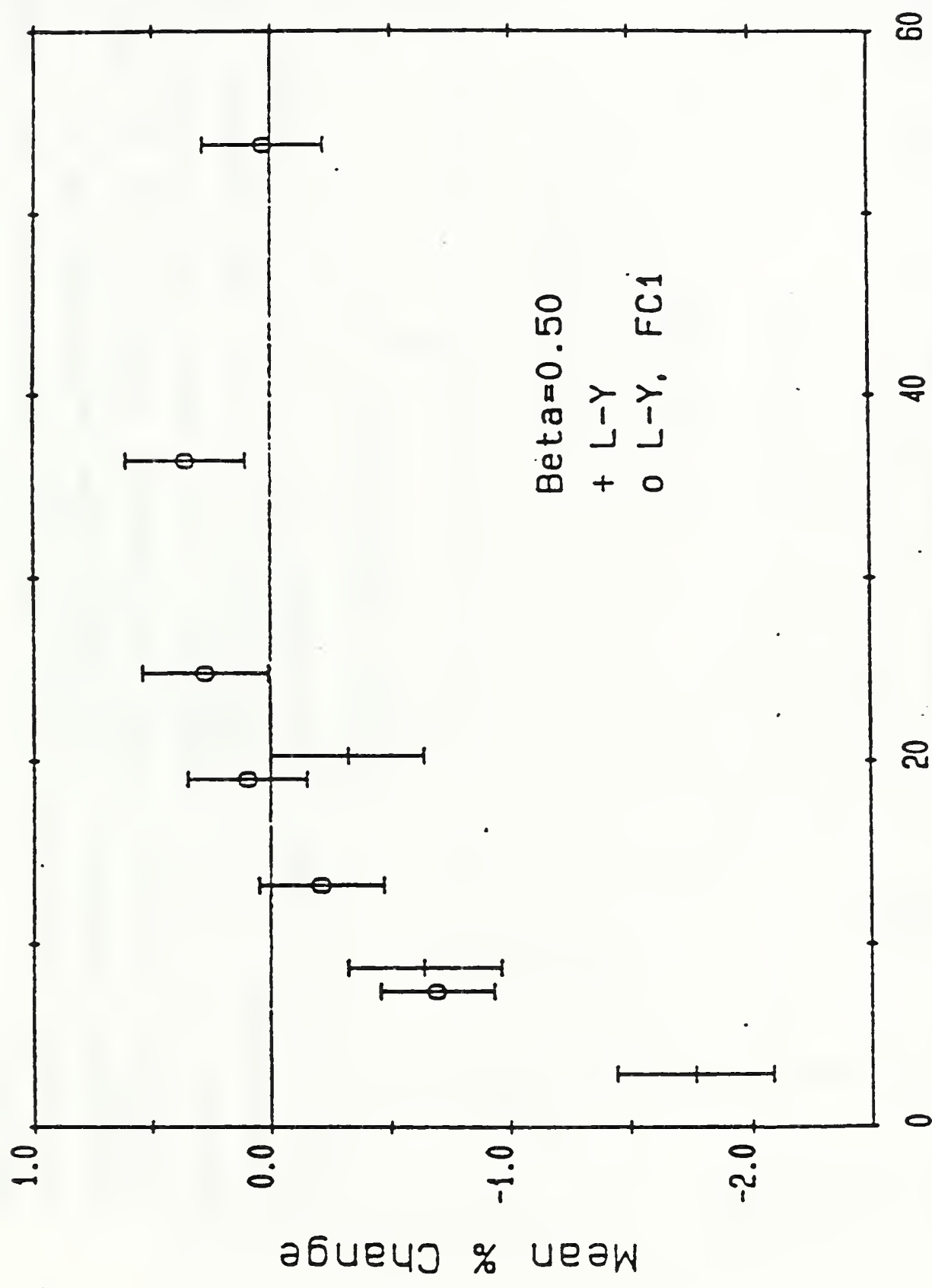

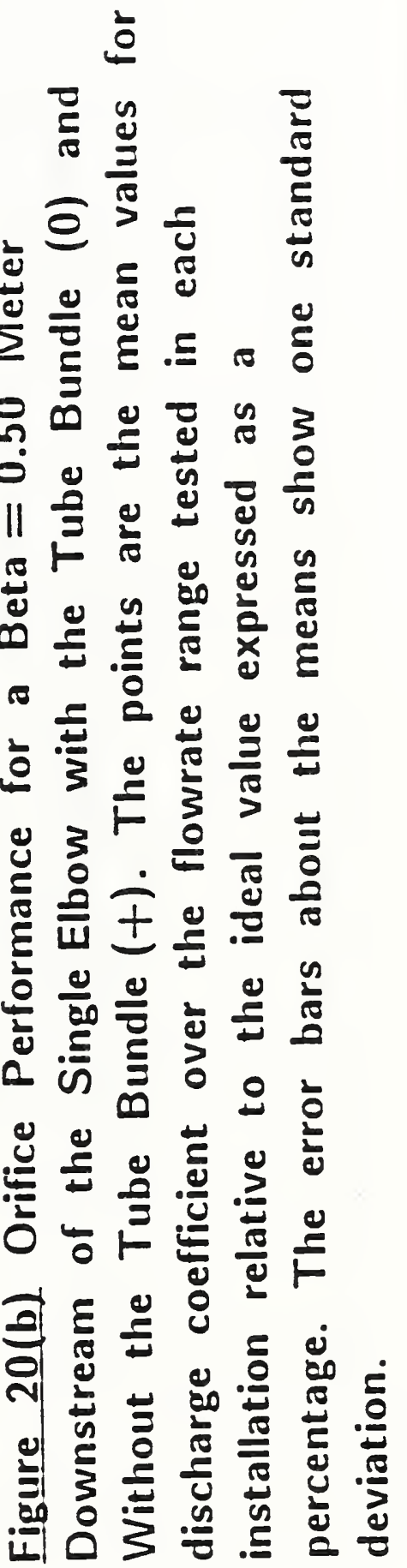



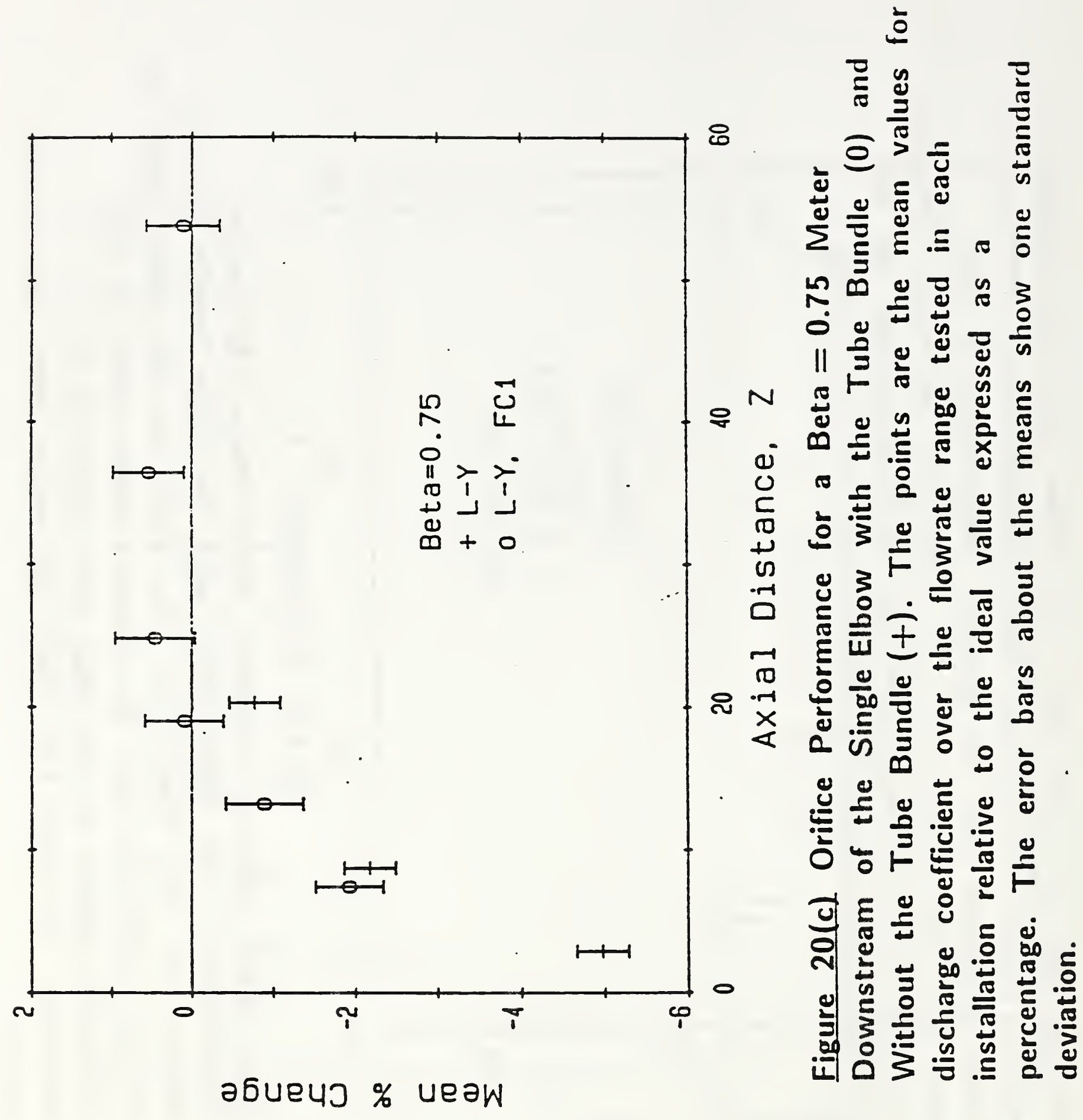


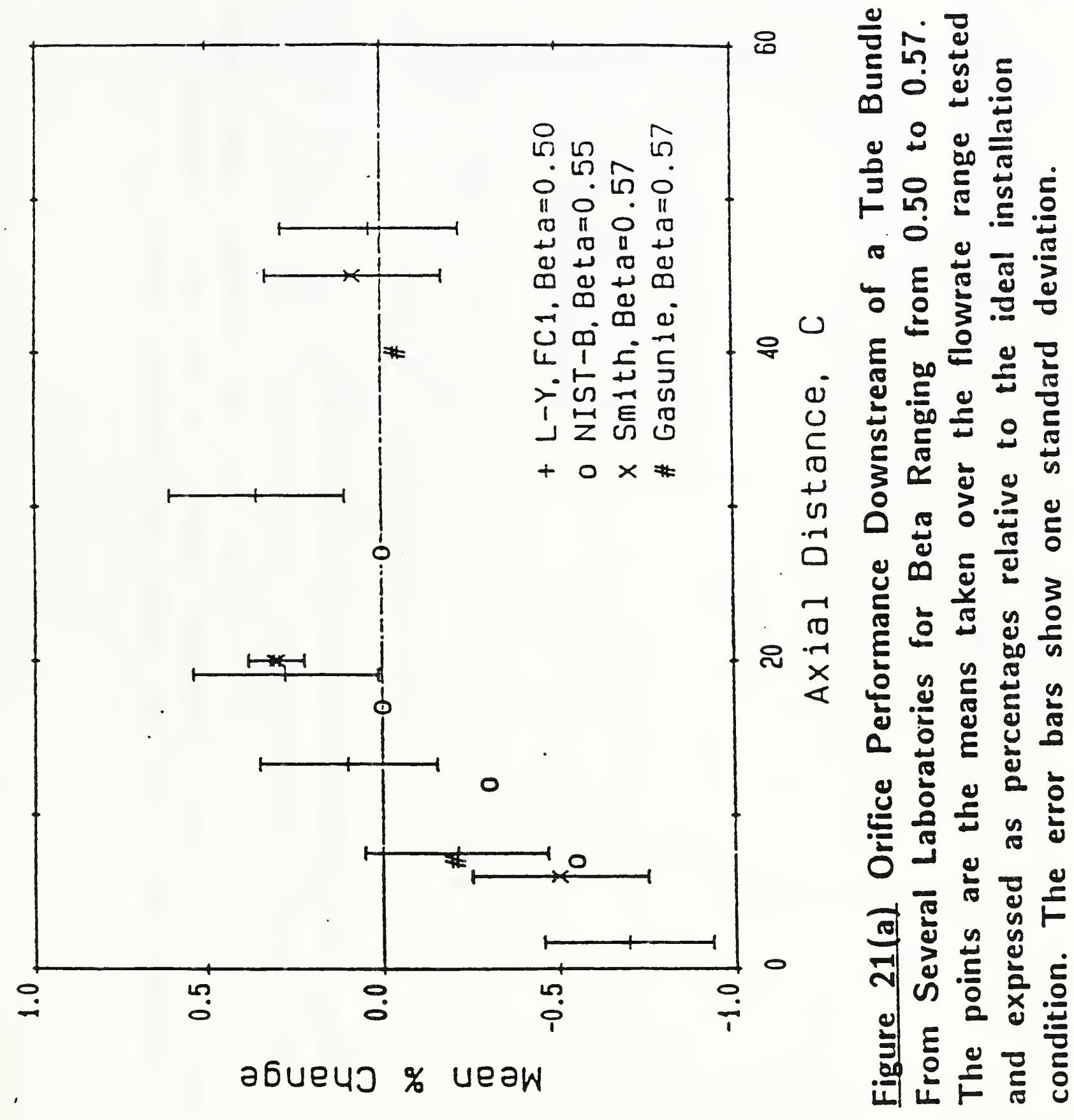




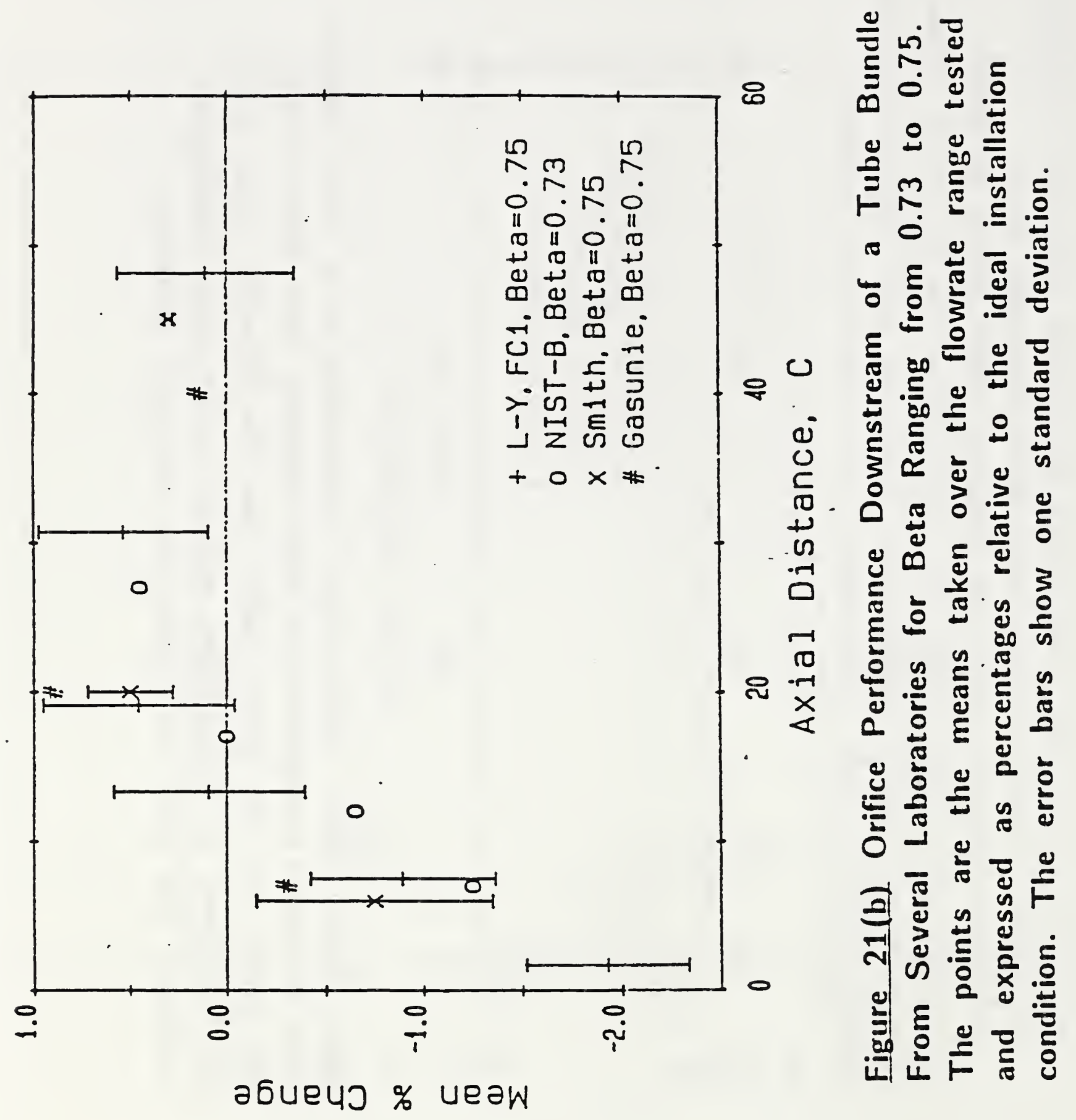




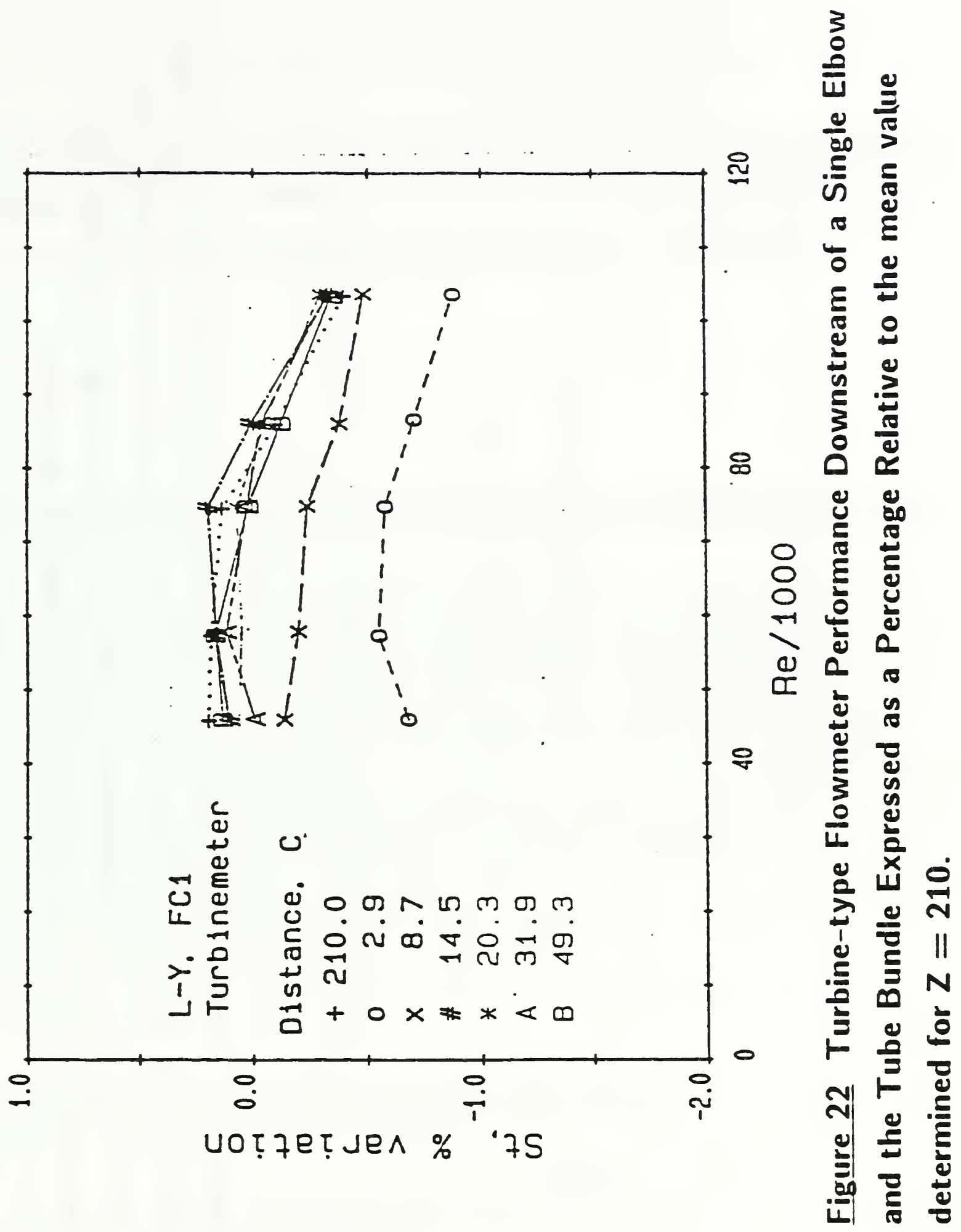




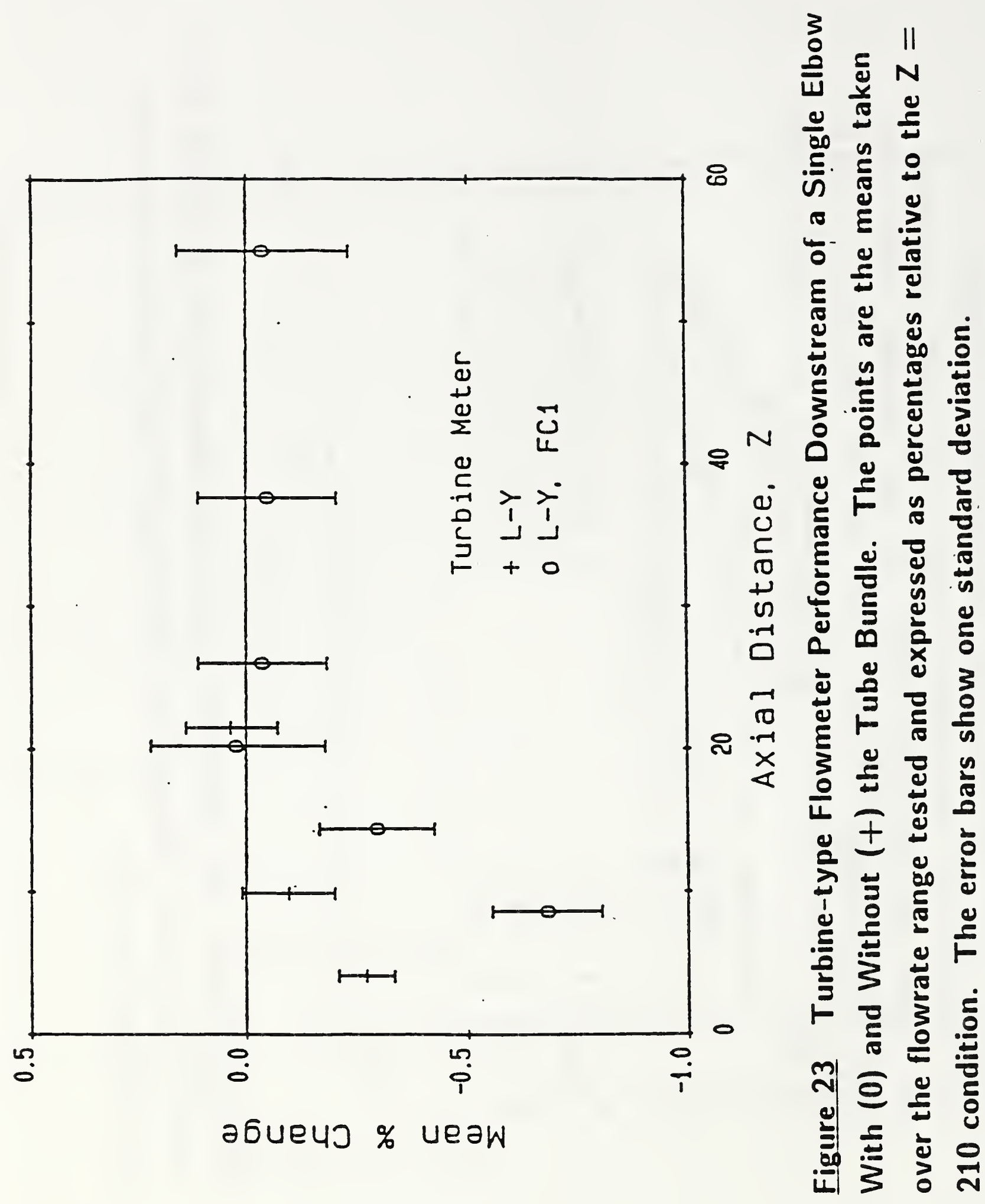




\section{BIBLIOGRAPHIC DATA SHEET}

\begin{tabular}{|c|c|}
\hline 2. & PERFORMING ORGAMIZATION REPORT NUMBER \\
\hline & $\begin{array}{l}\text { PUBLCATION DATE } \\
\text { MAY } 1990\end{array}$ \\
\hline
\end{tabular}

\section{TITLE AND SUBTITLE}

NIST's Industry-Government Consortium research Program on Flowmeter Installation Effects: Summary Report with Emphasis on the Research Period November 1988 - May 1989

\section{AUTHOR(S)}

G.E. Mattingly and T.T. Yeh

6. PERFORMING ORGANIZATION (IF JOINT OR OTHER THAN NIST, SEE INSTRUCTIONS)

U.S. DEPARTMENT OF COMMERCE

NATIONAL INSTITUTE OF STANDARDS AND TECHNOLOGY

GAITHERSBURG, MD 20899

7. CONTRACT/GRANT NUMBER

8. TYPE OF REPORT AND PERIOD COVERED

\section{SPONSORING ORGANIZATION NAME AND COMPLETE ADDRESS (STREET, CITY, STATE, ZIP)}

\section{SUPPLEMENTARY NOTES}

DOCUMENT DESCRIBES A COMPUTER PROGRAM; SF-185, FIPS SOFTWARE SUMMARY, IS ATTACMED.

11. ABSTRACT (A 200-WORD OR LESS FACTUAL SUMMARY OF MOST SIGMIFICANT INFORMATION. IF DOCUMENT INCLUDES A SIGNIFICANT BIBLIOGRAPHY OR UTERATURE SURVEY, MENTION IT HERE.)

This report presents results produced in a consortium-sponsored research program on Flowmeter Installation Effects. This project is a collaborative one that has been underway for four years; it is supported by an industry-government consortium that meets twice yearly to review and discuss results and to plan subsequent phases of the work. This report contains the results and conclusions of the recent meeting of this consortium at NIST-Gaithersburg, MD in May 1989.

The objective of this research program is to produce improved flowmeter performance when meters are installed in "non-ideal" conditions. This objective is being attained via a strategy to (A) measure, understand, and quantify the salient features of the "non-ideal" pipe flows from such pipeline elements as elbows, reducers, valves, flow conditioners, etc. or combinations of these, (B) to correlate meter factor "shifts" for selected types of flowmeters, relative to the features of these "non-ideal" pipe flows so as to be able to accurately predict meter performance in "non-ideal" installations, and (C) disseminate the resulting technology through appropriate channels such as publishing our results in pertinent journals and upgrading "paper" standards for flow measureñent.

12. KEY WORDS (6 TO 12 ENTRIES; ALPHABETICAL ORDER; CAPITALZE ONLY PROPER NAMES; AND SEPARATE KEY WORDS BY SEMICOLONS)

Fluid Metering; Flow Conditioning: Flow Measurement; Installation Effects; Standards research; Tube Bundles

\section{AVAILABIUTY}

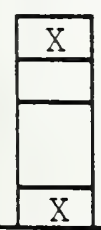

UNUMITED

FOR OFFICIAL DISTRIBUTION. DO NOT RELEASE TO MATIOMAL TECHNICAL IMFORMATION SERVICE (NTIS).

ORDER FROM SUPERINTENDENT OF DOCUMENTS, U.S. QOVERMMENT PRINTING OFFICE, WASHINOTON, DC 20402.

ORDER FROM MATIONAL TECHNICAL IMFORMATION SERVICE (NTIS), SPRINGFIELD, VA 22161.
14. NUMBER OF PRINTED PAGES

59

\section{$\mathrm{A} 04$}




